NASA Technical Memorandum 88941

\title{
The Effect of Nonlinearities on the Dynamic Response of a Large Shuttle Payload
}

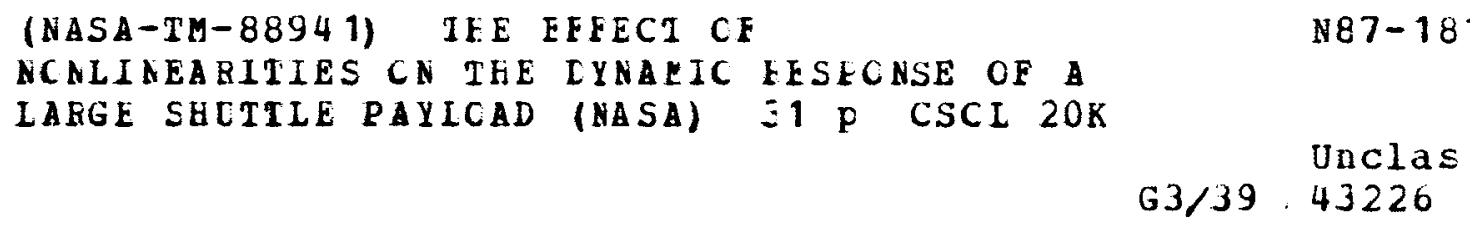

Timothy L. Sullivan and Kelly S. Carney

Lewis Research Center

Cleveland, Ohio

Prepared for the

28th Structures, Structural Dynamics, and Materials Conference sponsored by the American Institute of Aeronautics and Astronautics Monterey, California April 6-8, 1987 
THE EFFECT OF NONLINEARITIES ON THE DYNAMIC RESPONSE OF A LARGE SHUTTLE PAYLOAD

Timothy L. Sullivan and Kelly S. Carney

National Aeronautics and Space Administration

Lewis Research Center

cleveland, oh io 44135

\section{Abstract}

The STS Centaur was designed to be a high energy upper stage for use with the Space Shuttle. Two versions were designed and under development when the program was cancelled. The first version, designated G-prime, was designed for planetary missions. The second version, designated $G$, was designed to place spacecraft in geosynchronous orbit. As a part of the STS Centaur finite-element model verification effort, test articles of both versions were subjected to a series of static tests. In addition the Centaur G-prime test article was subjected to a series of dynamic tests including a modal survey. Both the static and dynamic tests showed that nonlinearities existed in the Centaur and its support system. The support system included flight-like latches. The nonlinearities were particularly apparent in tests that loaded the forward support structure of the Centaur. These test results were used to aid in the development of two improved finite-element models. The first was a linear model, while the second contained nonlinear elements at the boundaries. Results from both models were compared with the transient response obtained from a step-relaxation or twang test. The linear model was able to accurately match the low frequency response found in the test data. However, only the nonlinear model was able to match higher frequency response that was present in some of the test data. In addition the nonlinear model was able to predict other nonlinear behavior such as the dynamic "jump" that occurs in systems with nonlinear stiffness.

\section{Introduction}

An important aspect in the design of reliable structures is the availability of accurate design loads. In the design of aerospace structures to dynamic loads this requires knowledge of forcing functions (a "given" for Space Shuttle payloads), 1 and an accurate representation of the stiffness, mass, damping, and boundary conditions of the payload. The usual method of representation is the finite element model (FEM). One requirement for flying on Shuttle is that test data verify the accuracy of the FEM. 1

The Centaur $\mathbf{G}$ and $\mathbf{G}$-prime $2-6$ are two high performance upper stages designed for use in the Space Transportation System (STS). NASA's Lewis Research Center had management responsibility for the design, development, and test of these two stages. General Dynamics Space Systems Division performed the work under contract to NASA. NASA and the Department of Defense jointly funded the program. Centaur $G$ has the design capability of placing spacecraft weighing greater than 5 tons into geosynchronous orbit. Centaur G-prime was designed primarily for planetary missions and was scheduled to launch Galileo to Jupiter 7 and Ulysses to the sun in May of 1986. Following the Shuttle Challenger $51-L$ accident on January 28,1986 , safety 8 and other considerations involved with integrating Centaur into Shuttle were reevaluated.
This reevaluation resulted in the cancellation of the Shuttle/Centaur program by NASA on June 19, 1986 .

Before cancellation, as a part of the FEM verification effort, Centaur G-prime had undergone a complete set of stiffness and dynamic tests. Stiffness testing of Centaur $G$ had started and at the time of cancellation two component tests had been completed. While at present it is unlikely that the test results will be applicable to Centaur flying in Shuttle, some of the results were of a general nature with potential applicability to other Shuttle payloads. Foremost among these were nonlinear effects. Three types of nonlineartities were identified during the Centaur G/G-prime verification effort. The first was a structural nonlinearity in the forward support structure of the Centaur. The other two nonlinearities were associated with the interface between Centaur and Shuttle. This interface is a trunnion (Centaur) to latch/rail (Shuttle) connection and has gapping and friction noninearities. The effect of trunnion friction on payloads is a topic of significant study $9-13$ and debate.

This paper will briefly describe Centaur G/Gprime and their support systems both in the Shuttle and during test. It will document the nonlinearities measured during stiffness testing. The dynamic response of Centaur G-prime was obtained in several ways. The first was a modal survey. Here the paper will concentrate on the steady state response at five resonant frequencies (sine dwell excitation). Pretest analysis showed that these five modes were the important loads producing modes. In addition, the paper presents the dynamic response of one highly nonlinear mode to sine sweep excitation. Finally, the paper presents the transient response of Centaur G-prime to step-relaxation (twang) excitation. The results of various linear and nonlinear analytical approaches available in the NASTRAN FEM computer program 74 and taken to improve test/ analys is correlation will be shown. Comparison between test and analysis will be made from both time histories and response spectra analysis. Conclusions will be drawn concerning the relative importance of the various types of nonilnearities investigated.

\section{Centaur Configurations}

Figure 1 shows the two STS Centaur configurations. Centaur is a high energy liquid hydrogen/ liquid oxygen upper stage. The tanked weight of Centaur $G$ is approximately 37000 lb while that of G-prime is 50000 1b. Structurally, the STS Centaur consists of the following components. Starting at the forward end and referring to $\mathrm{Fig} .2$, the first component is the forward adapter. The forward adapter consists of a conical aluminum section (riveted ring, stringer, skin construction) and a graphite/epoxy cylindrical section. The conical section serves as a mounting platform for avionics and other equipment. The forward support structure attaches to the forward end of the conical adapter. It consists of three titanium beams supported by 
boron/aluminum struts. The outer ends of these beams are the forward interface location between Centaur and Shuttie. The next components are the two pressure stabllized, welded stainless steel cryogenic propellant tanks. The liquid oxygen tank interfaces with a second graphite/epoxy adapter, the aft adapter. The final two major structural components are the deployment adapter and the Centaur support structure (CSS). Both are riveted aluminum structures. They provide the load path between the aft end of Centaur and the orbiter, and remain with the orbiter after Centaur deployment.

The STS Centaur was designed to interface with latches in the Shuttle orbiter at eight places as shown in $\mathrm{Fig} .2$. With two exceptions each trunnion carries primary loads in only one direction and is free to slide restrained only by friction in the other two directions. The exceptions are the Centaur support structure (CSS) forward sill trunnions which carry both $X$ - and Z-direction loads. There are a total of 14 sliding locations between Centaur and Shuttle. Figure 3 shows a photograph of a typical trunnion-to-latch connection. For deployment the forward sill latches release and Centaur is rotated to a $45^{\circ}$ angle. This rotational capability results in four additional sliding locations in Centaur between the deployment adapter and CSS.

There are two types of nonlinearities associated with these latches. The first is due to necessary clearances between the trunnion and latch and between the latch and rall. Loading eliminates these clearances but whlle this is happening the joint reacts at a reduced spring rate. The second nonlinearity is due to sliding between trunnion and latch and between latch and rail. Friction can cause nonlinear motion here depending on the normal force, friction coefficient, and driving force. If the product of the normal force and friction coefficient exceeds the driving force, the joint will stick. If this product is less than the driving force, the joint will slide. Figure 4 presents a time history from the Centaur G-prime twang test demonstrating this phenomenon.

The major element in Centaur that behaved in a nonlinear manner was the forward support structure, shown in Fig. 5. As the figure shows, there are five joints associated with each trunnion. They are clevis-type joints with spherical bearings to maintain a pinned end constraint. The nonlinearity is due to clearances in the clevis bolts and bushings and initial compression of the Teflon liner in the spherical bearings. The joint requires a force of about 1000 1b before it achieves its full stiffness. This nonlinearity is in series with trunnion gapping. For modeling purposes, there was no attempt to separate the two effects. In this paper the combined effect is referred to as the stiffness nonlinearity.

\section{Model Verification Testing and Nonlinear Results}

This section defines the scope of the testing done to verify the SIS Centaur mathematical models and presents results that show the types of noninearities encountered during this testing.

\section{Scope of Testing}

For structural dynamics modeling it was important to consider the STS Centaur in two configurations. The first is called the cargo element configuration. This represents the Centaur in the orbiter bay, supported in latches as described earlier. This is the configuration used in calculating 1ift-off loads as well as abort maneuver and landing loads. The second configuration is the free flight configuration attained after Centaur is deployed and separated from the orbiter. For testing, this configuration was simulated by suspending Centaur from the forward end on springs. This configuration is also important in control dynamics studies. The testing was designed to provide data for checking the important characteristics of both configurations. The results of the free flight configuration tests are not included in this report.

Table 1 summarizes the testing conducted to verify the STS Centaur FEM stiffness representation. In the cargo element configuration the stiffness of the supporting structure determines to a large degree the dynamic response of the Centaur. At the forward end this is the forward adapter and forward support structure and at the aft end, the CSS. Because of the importance of the CSS stiffness, both the $G$ and $G$-prime versions were subjected to component stiffness tests. Figure 6 shows the loading conditions for these tests. The Centaur $G$ forward adapter including its forward support structure was al so subjected to a component stiffness test. Figure 7 gives the loading conditions. The final series of stiffness tests were conducted on Centaur G-prime in the cargo element configuration.

Figure 8 gives these loading conditions.

For dynamic testing in the cargo element configuration, the centaur was held in flight-like latches that were supported in one of two ways. The forward end was supported by a low-stiffness structure while the aft end was supported in highstiffness structures. Both support methods were designed to minimize dynamic interaction between Centaur and its support. At the forward end the latches were attached to the forward reaction frame. This frame was supported on air bags and loaded with weights to produce a natural frequency well below the range of interest. The aft end latches were supported by high-stiffness stanchions. In the primary load directions the stanchions were designed to have a minimum stiffness of $750000 \mathrm{ib} / \mathrm{in}$. Basically, two types of dynamic tests were conducted. The first was a series of four step-relaxation tests to determine transient response. Test parameters are given in Table 2 and a sketch of the test setup is shown in Fig. 9 . The second type of testing was modal testing. 15,16 Modal response was determined using random, sine sweep, and sine dwell excitation. In the cargo element configuration testing was conducted with the liquid oxygen tank either full of water or empty. Filling the tank with water added about $32000 \mathrm{lb}$ of mass to the system. In addition, two types of boundary conditions were tested. For the first type the friction directions at the boundaries were free to move without mechanical restraint. For the second type a majority of the friction directions were mechanically restrained from siliding.

For the cargo element configuration, the results of random testing was used primarlly as a preliminary method for ldentifying modes. Final mode characterization was based on high force level sine dwell excitation where the effort was concentrated on modes that pretest analys is showed were major load producers. The sine dwell force level 
was varied to determine this effect on modal characteristics. The sine sweep data was used primarily to help identify closely spaced modes.

To describe the nonlinearities existing in STS Centaur and in its interface with Shuttle, only a small subset of the tests described above are required. Cargo element stiffness test conditions 2 and 3 defined the stiffness noninearity at the forward end of Centaur while supported in latches. Test conditions 1 and 5 of the Centaur $G$ forward adapter stiffness test defined the magnitude and source of the nonlinearity in the Centaur alone. In the dynamic area, sine sweep excitation that loaded the forward end of Centaur G-prime in the pitch direction showed the "jump" associated with resonance in nonlinear systems. Sine dwell data for the liquid oxygen tank full of water and the friction boundaries free to slide provided the data that will be presented to show the effect of force level on the frequency of the important modes. And step-relaxation test 2 combined nonlinear stiffness and friction in a single transient response.

\section{Nonlinear Results}

Test conditions 2 and 3 of the Centaur G-prime cargo element stiffness tests defined a nonlinearity associated with the Centaur forward support structure in series with the trunnion-to-latch connection at the forward end. Figure 10 shows the load point force-displacement relationships for these two tests. Figure 10(a) shows the yaw or Y-direction loading results. The data points are for loading from $5000 \mathrm{lb}$ through zero to $-10000 \mathrm{lb}$. The figure shows that the nonlinear behavior can be approximated as bllinear behavior by fairing three straight lines through the data. The smaller slope is less than 40 percent of the larger slope. A load point force of about 1000 1b was required before the higher slope was achieved. Figure $10(b)$ shows the pitch or Z-direction loading results. Here the data show loading from 5000 ib through zero to $-20000 \mathrm{lb}$. Again, a bilinear approximation of the test data looks reasonable. The ratio of the two slopes is about the same as for yaw loading. If the data are centered about the origin, a force of about $1500 \mathrm{lb}$ is required to achieve the higher slope. This relates to a reaction force of about 1000 ib on each sill trunnion at the interface with its latch.

The nonlinear behavior shown in $\mathrm{Fig} .10$ represents a combination of the nonlinearity in the trunnion/latch/rail connection and that in the forward support structure. There was not enough instrumentation in the test to accurately separate the contribution from the two sources. The Centaur $G$ forward adapter stiffness test provided an opportunity to estimate the contribution of the forward support structure alone. Figure 11 shows load point response as well as displacement across one joint. Figure 11(a) shows sill beam response. These data show that the deviation from linearity at the load point takes place at the same time there is a very significant softening of the joint. This leads to the conclusion that the joints are the source of the load point nonlinearity. The reduced stiffness takes place over a change in load of about $2500 \mathrm{lb}$ or \pm 1250 1b. Figure 11 (b) shows the keel beam response. Results are similar to those of the 5111 beam. Reduced stiffness here is present over a change in load of about $2800 \mathrm{lb}$ or $\pm 7400 \mathrm{lb}$. The forward adapter stiffness test data show that a significant nonlinearity exists in the forward support structure. Therefore, the forward support structure was a significant contributor to the nonlinear response found in Centaur G-prime testing.

Dynamically, the stiffness nonlinearities just described had their most significant effect on modes that loaded the forward support structure, particularly the forward pitch mode. Figure 72 shows the response of this mode to sine sweep excitation. The plot is a time history of si11 trunnion reaction force. The peak excitation force was a constant $250 \mathrm{lb}$ applied to the simulated spacecraft in the Z-direction and excitation frequency was increasing at a constant rate of about $0.03 \mathrm{~Hz} / \mathrm{sec}$. The peak response occurred at a frequency of $7.5 \mathrm{~Hz}$. The rapid drop off in response is typical of systems containing nonlinear stiffness elements.

Figure 13 shows the effect of excitation force on modal frequency for the forward pitch mode and four other important modes. Random excitation test results are also shown in this figure. The behavior shown in the figure is the result of two opposing nonlinear effects. The first effect is friction. At low force levels the trunnion/latch joints stick increasing system stiffness and natural frequency. At higher force levels the joints slide, reducing the stiffness and natural frequency. This effect was examined analytically with the pretest FEM by using two sets of boundary conditions. In the first set all trunnions were free to slide in the friction directions. For the second set all the trunnions directly loaded by gravity were fixed in the friction direction. Table 3 gives the results of doing this. These results show that friction restraint shouid have a significant effect on the axial mode, a moderate effect on the yaw modes and little or no effect on the pitch modes.

The stiffness nonlinearity, having the characteristics of a hardening spring, causes an increase in frequency with increasing force level. This nonlinearity will have the greatest effect on modes that load the forward end of Centaur. For the force levels used in the modal survey, the joint friction effect appears to predominate on four of the modes. only the forward pitch mode increased in frequency. Qualitatively, at least, the results shown in Fig. 13 agree with the expected effects of the two nonlinearities.

\section{Development of a Nonlinear Model Using NASTRAN}

The NOLIN1 element avallable in NASTRAN was used to model the stiffness nonlinearity in the Shuttle/Centaur system. The stiffness nonlinearity was a result of nonlinearity in the forward support structure of Centaur in series with the nonlinearity at the trunnion/latch interface. The combination could, therefore, be modeled as a single nonlinearity. The NOLINT elements were placed at the trunnion-to-latch interface. Figure 14 shows this schematically. Figure 15 shows the force/displacement properties of the NOLIN 1 element used in the model. These properties were based on the stiffness test data shown in Fig. 10(b).

To check the operation of the NOLIN1 elements for correctness, the direct transient solution was used for a static load applied at the simulated spacecraft. The load/displacement results are compared to the test data in Fig. 16. While the mode? did not track the test data precisely, the agreement 
was close enough to use the model for subsequent nonlinear transient analysis.

This model was also used in an attempt to simulate the response of the forward pitch mode to sine sweep excitation shown in $\mathrm{Fig} .12$. The simulation was done by applying sine dwell excitation in a stepwise fashion through the frequency range of interest again using the direct transient solution. Four excitation farce levels were applied: $250,500,1000$, and $20001 \mathrm{~b}$. Figure 17 shows the results of this simulation for a forward sill trunnion reaction force. For the 250 lb excitation force case, peak response occurred at $7.7 \mathrm{~Hz}$ compared to $7.5 \mathrm{~Hz}$ obtained during the sine sweep test. Figure 18 shows the change in resonance frequency with increased driving force predicted by the analysis and compares it to test data. At high driving force levels the frequency asymptotically approaches $11 \mathrm{~Hz}$, the frequency of the forward pitch mode without the NOLINI element. The good agreement between dynamic test and anaiys is provides additional evidence that the NOLIN1 element adequately represents the stiffness nonlinearity.

\section{Test/Analysis Correlation for Centaur G-Prime Transient Response}

This section presents a comparison of test and analytical results in both the time domain and frequency domain for the step-relaxation test. Table 4 gives some detalls about the three analytical models used in this comparison. As a basis for comparison between test and analysis, several representative sensors were selected. Referring to Fig. 9, they were acceleration in the simulated spacecraft (A1Z), acceleration at the interface between the simulated spacecraft and spacecraft adapter (A2Z, A4Z), reaction force at the forward support structure left sill trunnion (RIZ), and reaction force at the CSS left forward (R5Z) and aft (RTZ) sill trunnions.

Figure 19 presents time history results for the GP5.0 model for four locations along the length of the structure. The results are in poor agreement with the test data. The response of the model is much less than measured at the forward end of the Centaur (sensors $A 1 Z$ and $R I Z$ ) while greater than measured at the aft end (sensors $R 5 Z$ and $R 7 Z$ ).

Figure 20 presents resuits from the post-test linear mode1, GP6.0M, for the same four locations. The agreement between test and analys is is greatly improved and at each location the measured response is bounded by the analytical results. For the first 2 or 3 cycles the model tracks the test data with good accuracy but beyond this the agreement degrades. The comparison shows that the model is too heavily damped at the aft end. This is a result of using 4.6 percent structural damping when in reality the damping is concentrated at the forward end where the joints are located.

Figure 21 presents the nonlinear model (GP6.ONL) results. This model provides a silghtiy more accurate representation of the measured response for the inftial part of the time history. In general the difference in response between the GP6.OM and GP6.ONL models appears slight. Both models would benefit from a better distribution of damping with most of the damping concentrated at the forward end.
The real contribution of the nonlinear model is 1 llustrated in the response spectra plots presented in Figs. 22 and 23 . Figure 22 compares the measured response on the simulated spacecraft with results from the GP6.0M and GP6.ONL models. The linear model appears to provide a good match in frequency content while the nonlinear model shows additional mid- $(26 \mathrm{~Hz}$ ) and high-frequency (41 $\mathrm{Hz}$ ) content that is not apparent in the test response. However, at the interface between the simulated spacecraft and its adapter (A2Z, A4Z), the test results show frequency content at the mid-and high-frequency levels. The higher frequencies do not appear in the linear model results while they are present in those for the nonlinear model. These results show that the nonlinear representation is necessary in order to reproduce the full spectrum of frequencies.

\section{Concluding Remarks}

Static and dynamic testing of the centaur G-prime in the cargo element configuration showed that significant nonlinearities existed in this system. Based on test data, two analytical models were developed. The first was a linear model. The second model contained nonlinear elements at the boundaries. The linear model accurately reproduced the low frequency response measured during testing. The nonlinear model reproduced this low frequency response as well as response at higher frequencles. This model was also able to reproduce other nonlinear behavior observed during the testing. The accuracy of both models would be improved by a more realistic distribution of damping.

This effort to improve correlation between test and analysis considered only one of the nonlinearities observed in testing Centaur (i.e.. a stiffness nonlinearity) and concentrated on a transient response that exercised only one predominate mode. The complete evaluation of the dynamic response of STS Centaur requires consideration of other nonlinear effects such as friction. Correlation with test data where other predominate modes were excited also needs to be investigated.

\section{References}

1. Goetz, R.C.. "Keynote Address," Proceedings of the Shuttle Payload Dynamic Environments and Loads Prediction Workshop, Vol. 1, JPL D-1347, Jet Propulsion Lab, Pasadena, CA, 1984. pp. 3-28.

2. Stofan, A.J.. "A High Energy Stage for the National Space Transportation System," IAF Paper 84-15, 0ct. 1984 .

3. Spurlock, 0.F., "Shuttle/Centaur - More Capability for the 1980's," IAF Paper 83-18, Oct. 1983 .

4. Muckley, E.T., "Shuttle/Centaur Project Perspective," OTV Propulsion Issues, NASA CP-2347, 1985, pp. 15-27.

5. Rector, W.F., III, "The Centaur Family--for Future Use with the Space Shuttle, "IAF Paper 82-02, Sept. 1982.

6. Peebles, C., "The New Centaur," Spaceflight, vol. 26, No. 5, Sept./Oct. 1984, pp. 358-360 
7. Berman, A.L., Mudgway, D.J., and Mckinney, J.C., "The 1986 Launch of the Galileo Spacecraft Via the Space Transportation System," The Telecommunications and Data Acquisition Report, E.C. Posner, eds., JPL-TDA-PR-42-72, Jet Propulsion Lab, Pasadena, CA, Feb. 1983. (NASA CR-170071)

8. Seastrom, J.W., "Safety Challenges of the Shuttle/Centaur Fluid Interface," AIAA, Paper 85-1323, July 1985.

9. Hunt, D., Adams, W., and Bock, T., "Dynamic Analysis of Structures with Friction Forces at Sliding Joints," Journal of Spacecraft and Rockets, Vol. 21, No. 2, Mar./Apr. 1984, pp. 175-179.

10. Henkel, E.E., Misel, J.E., and Frederick, D.H., "A Methodology to Include Static and Kinetic Friction Effects in Space Shuttle Payload Transient Loads Analysis," Shuttle Environment and Operations Meeting, AIAA, NY, 1983, pp. 171-177.

11. Misel, J.E., Nenno, S.B., and Takahashi, D., "Transient Response Dynamic Module Modification to Include Static and Kinetic Friction Effects," 12th NASTRAN User's Colloquium, NASA CP-2328, 1984, PD. 132-160.
12. Chapman, J.M., "A Friction Methodology for Space Shuttle/Payload Transient Loads Analyses," Proceedings of the Shuttle Payload Dynamic Environments and Loads Prediction Workshop, Vol. 2, JPL D-1347, Jet Propulsion Lab, Pasadena, CA, 1984, pp. 543-572.

13. Yang, I-Min and Hruda, R.F., "Transient Responses for Space Shuttle with Trunnion Friction," Proceedings of the Shuttle Payload Dynamic Environments and Loads Prediction Workshop, Vol. 2, JPL D-1347, Jet Propulsion Lab, Pasadena, CA, 1984, pp. 573-580.

14. Gocke 1, M.A., ed., MSC/NASTRAN Handbook for Dynamic Analysis, The MacNeal-Schwendler Corp., 1983.

15. Chen, J., et al., "Modal Test/Analys is Correlation for Centaur G-prime Launch Vehicle," 27th Structures, Structural oynamics and Materials Conference, AIAA, 1986, pp. 621-633.

16. Trubert, M., et al., "Centaur G-prime Modal Test," Presented at 57 th Shock and Vibration Symposium, New Orleans, LA, Oct. 14-16, 1986. 
TABLE 1. - STS CENTAUR STIFFNESS TESTS

\begin{tabular}{|c|c|c|c|}
\hline $\begin{array}{c}\text { Centaur } \\
\text { configuration }\end{array}$ & Component/system & $\begin{array}{c}\text { Number of } \\
\text { loading } \\
\text { conditions }\end{array}$ & Details \\
\hline G-prime & CSS & 5 & Fig. 6 \\
G-prime & Cargo element & 8 & Fig. 8 \\
G & Forward adapter & 6 & Fig. 7 \\
CSS & CSS & 6 & Fig. 6 \\
\hline
\end{tabular}

TABLE 2. - STEP-RELAXATION TEST PARAMETERS

\begin{tabular}{|c|c|c|c|}
\hline $\begin{array}{c}\text { Test } \\
\text { number }\end{array}$ & $\begin{array}{c}\text { Applied force, } \\
10^{3} \text { lb }\end{array}$ & Direction & $\begin{array}{c}\text { Lox tank } \\
\text { water leve 1 }\end{array}$ \\
\hline 1 & 15 & $Z$ & Full \\
2 & 30 & $Z$ & Full \\
3 & 15 & $Z$ & Empty \\
4 & 9 & $Y$ & Full \\
\hline
\end{tabular}


TABLE 3. - EFFECT ON NATURAL FREQUENCY

OF PREVENTING SLIDING IN GRAVITY LOADED TRUNNIONS

\begin{tabular}{|c|c|}
\hline Mode & $\begin{array}{l}\text { Ratio of frequency } \\
\text { (with restraint / } \\
\text { without restraint) }\end{array}$ \\
\hline Axial & 1.27 \\
Forward yaw/roll & 1.13 \\
Aft yaw & 1.10 \\
Aft pitch & 1.02 \\
Forward pitch & 1.00 \\
\hline
\end{tabular}

TABLE 4. - CENTAUR G-PRIME NASTRAN DYNAMIC MODELS

\begin{tabular}{|c|l|}
\hline $\begin{array}{c}\text { Model } \\
\text { designation }\end{array}$ & \multicolumn{1}{|c|}{ Description } \\
\hline GP5.0 & $\begin{array}{l}\text { Baseline model. 29 000 D0F model } \\
\text { statically reduced to 208 D0F. 2 per- } \\
\text { cent structural damping. St iffness } \\
\text { partially verified by test. }\end{array}$ \\
GP6.0M & $\begin{array}{l}\text { Basic FEM stiffness verified by test } \\
\text { data. Linear springs added at bound- } \\
\text { aries to force agreement with modal } \\
\text { survey frequencies. Structural damp- } \\
\text { ing incrased to 4.6 percent to agree } \\
\text { with modal survey results. } \\
\text { Linear springs replaced by bilinear } \\
\text { Spring based on stiffness test data. } \\
\text { Structural damping = 4.6 percent. }\end{array}$ \\
\hline
\end{tabular}




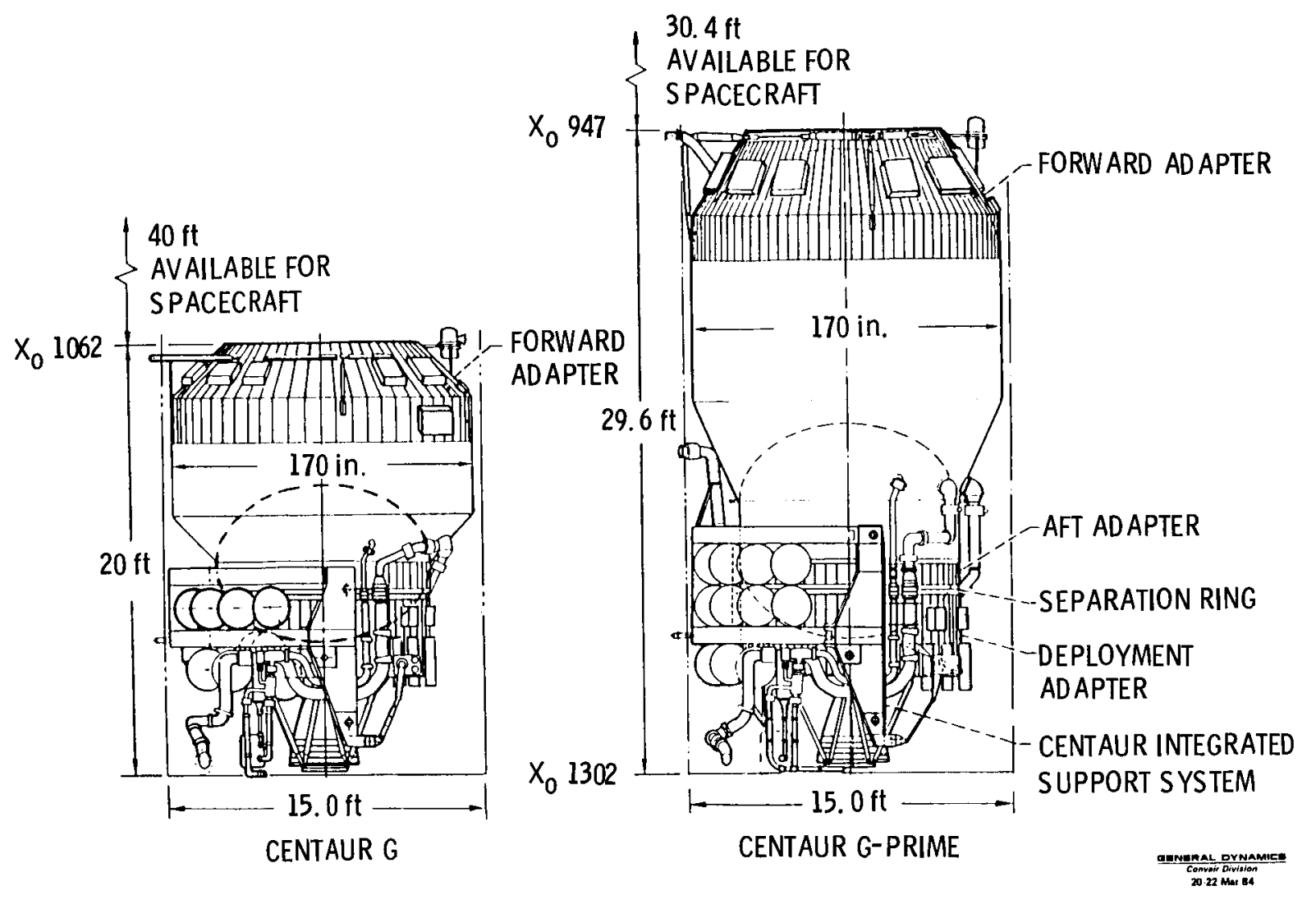

FIGURE 1. - STS CENTAUR CONFIGURATIONS.

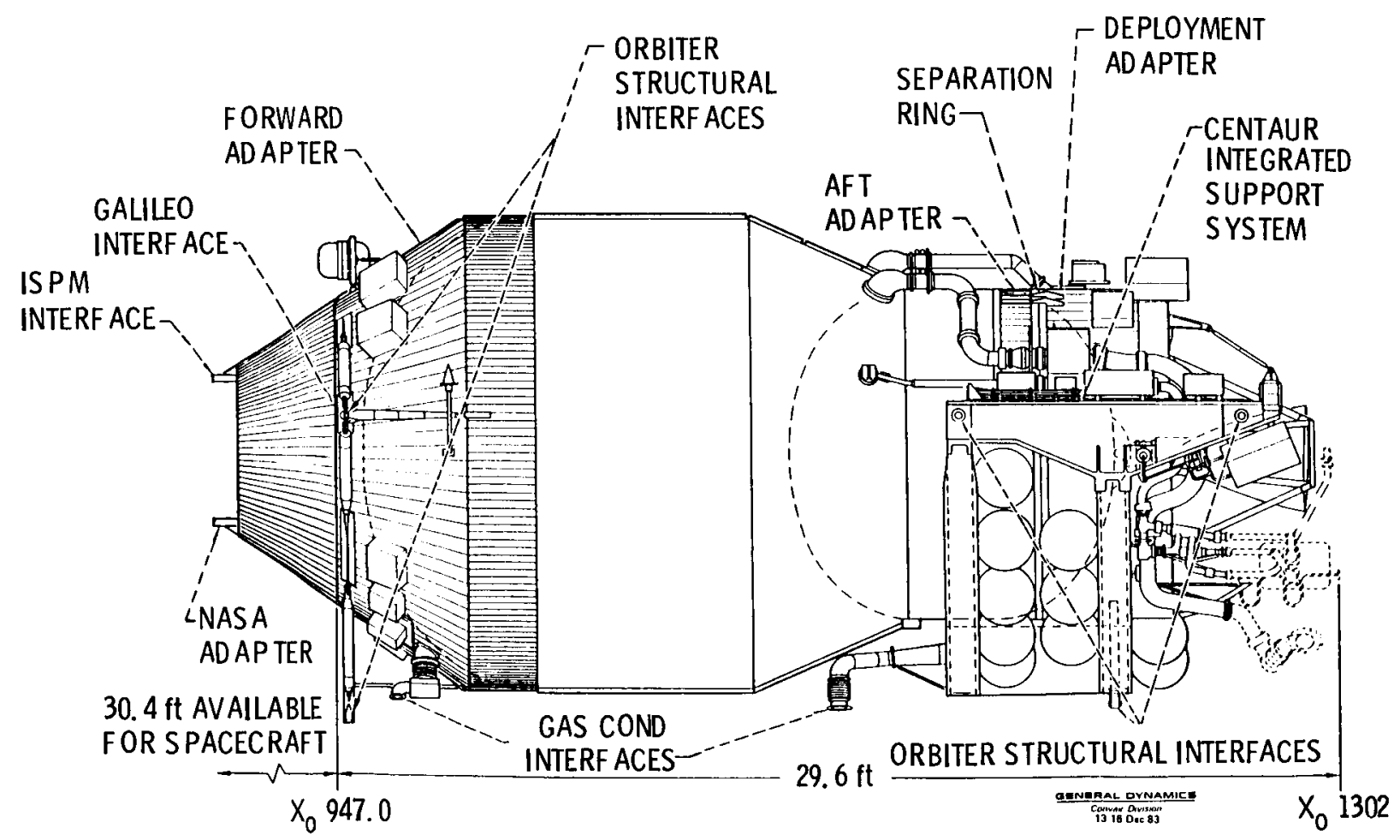

FIGURE 2. - MAJOR STRUCTURAL INTERF ACES FOR CENTAUR G-P RIME. 


\section{CRIGNAL PACE IS \\ OF POOR QUALITY}

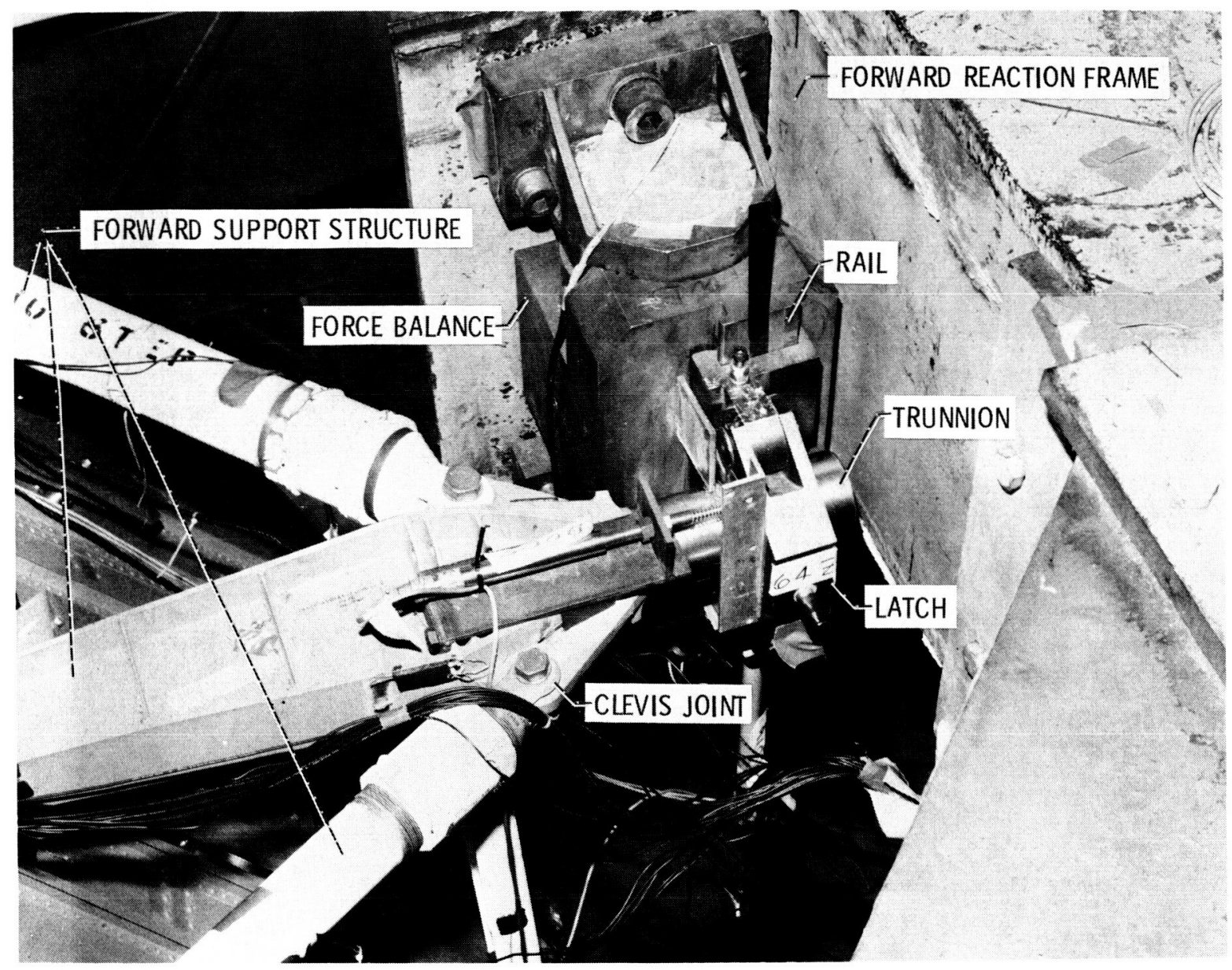

FIGURE 3. - TYPICAL CENTAUR TO SHUTTLE ORBITER INTERFACE.

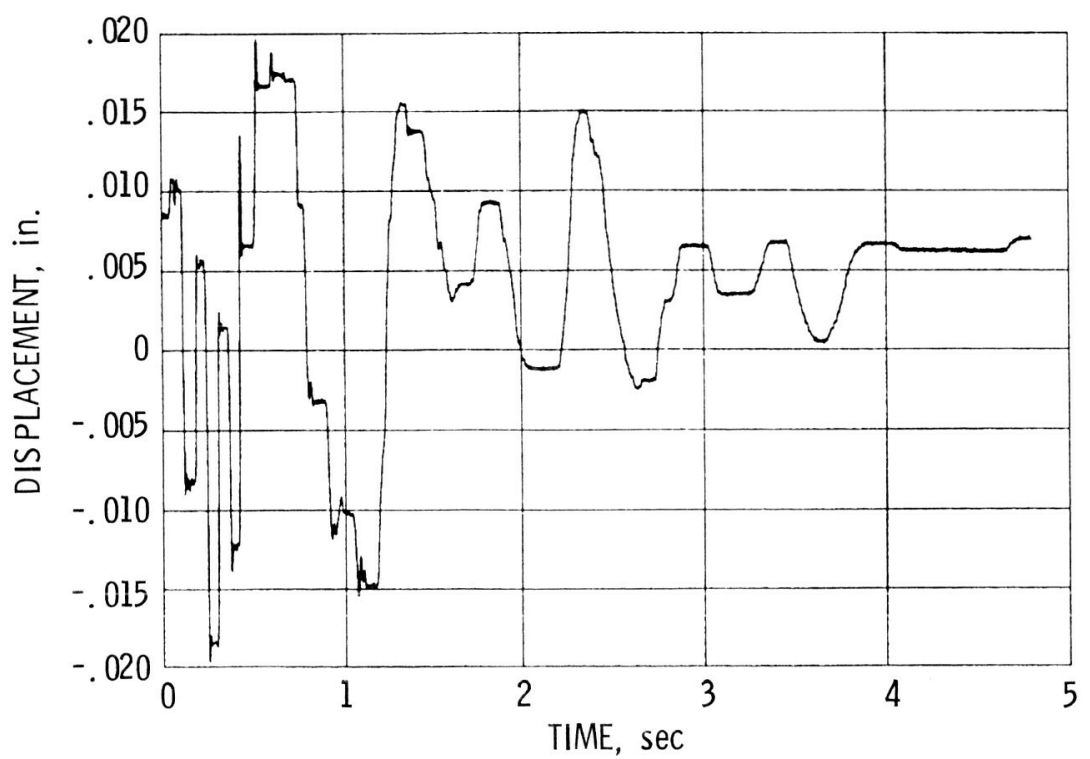

FIGURE 4. - TIME HISTORY OF LATCH-TO-RAIL RELATIVE MOTION FROM STEP-RELAXATION TEST (LVDT R2X). 

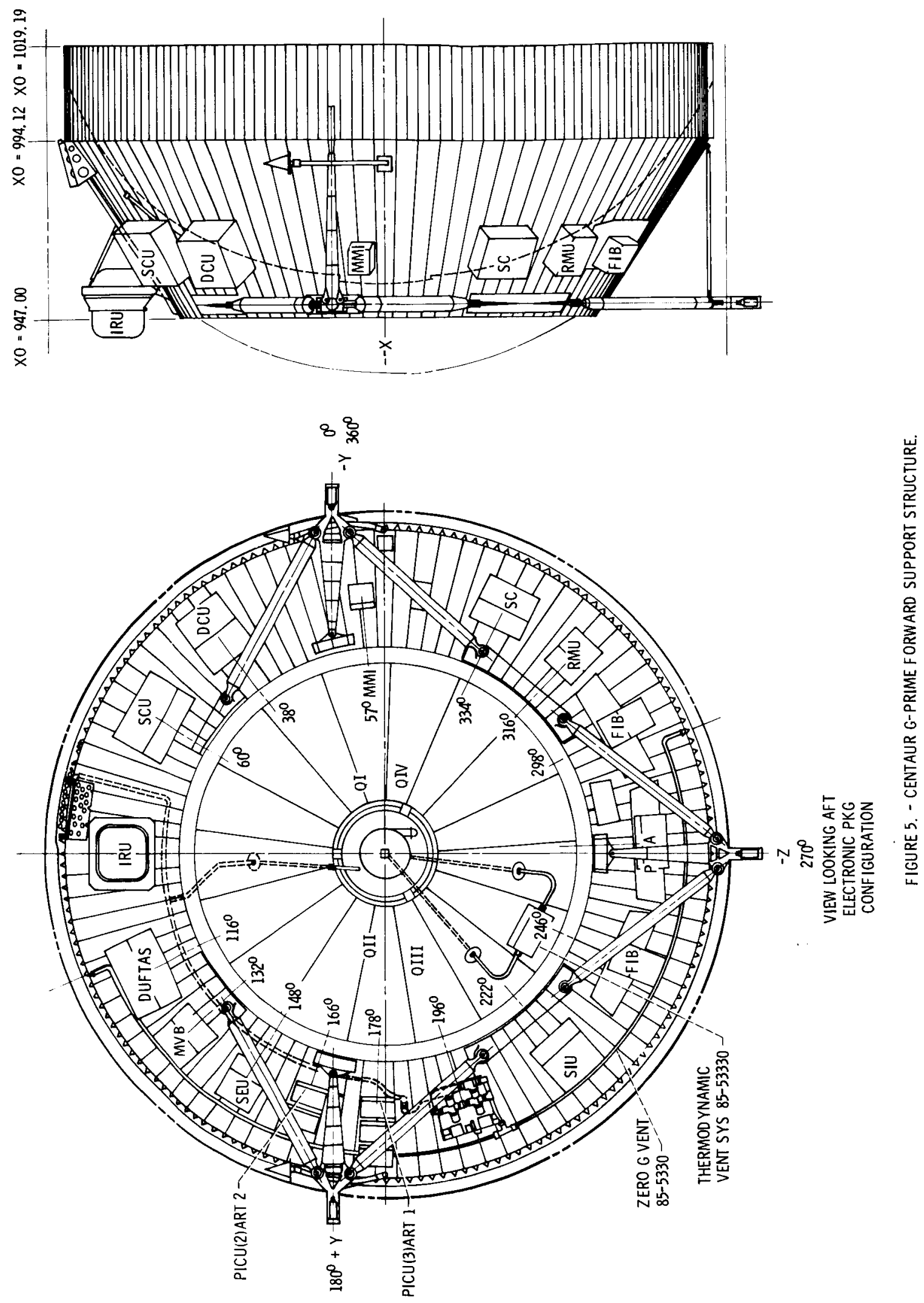


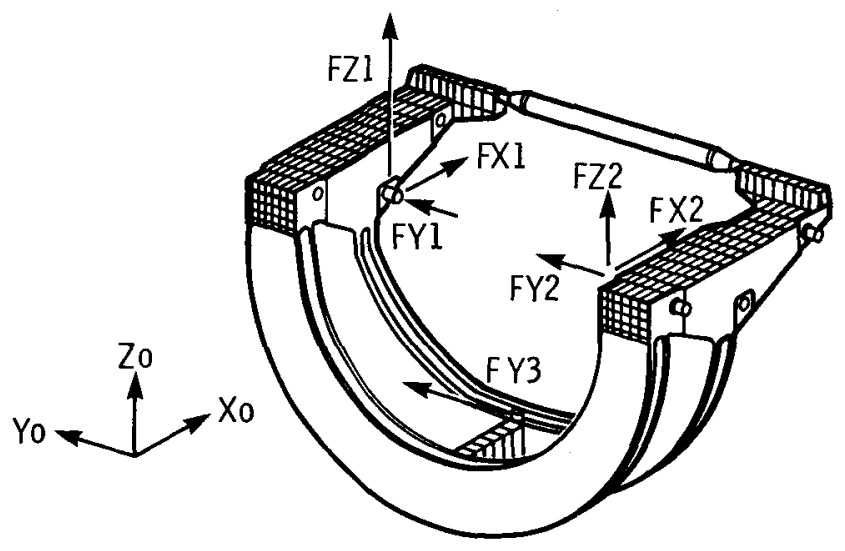

\begin{tabular}{|c|c|c|c|c|c|c|c|c|c|}
\hline \multirow{2}{*}{$\begin{array}{l}\text { CONFIG- } \\
\text { URATION }\end{array}$} & \multicolumn{2}{|c|}{ TEST CONDITION } & \multicolumn{7}{|c|}{ APPLIED LOAD, $10^{3} \mathrm{lb}$} \\
\hline & $\begin{array}{l}\text { NUM- } \\
\text { BER }\end{array}$ & DESCRIPTION & Fxl & $F \times 2$ & Fzl & $\mathrm{Fz2}$ & Fyl & Fy2 & Fy3 \\
\hline G-PRIME & $\begin{array}{l}1 \\
2 \\
3 \\
4 \\
5\end{array}$ & $\begin{array}{l}\text { SYMMETRIC X } \\
\text { SYMMETRIC Z } \\
\text { ASYMMETRIC X } \\
\text { ASYMMETRIC Z } \\
\text { LATERAL Y }\end{array}$ & $\begin{array}{l}50 \\
-8.5 \\
8.5 \\
-\cdots\end{array}$ & \begin{tabular}{l}
50 \\
\hdashline-8.5 \\
--- \\
---
\end{tabular} & \begin{tabular}{l|}
--- \\
35 \\
12.8 \\
$-\cdots$
\end{tabular} & $\begin{array}{l}---- \\
35 \\
-12.8 \\
-\cdots\end{array}$ & $\mid \begin{array}{c}--- \\
--- \\
--- \\
--- \\
--\end{array}$ & $\begin{array}{l}--- \\
--- \\
--- \\
--- \\
---\end{array}$ & $\begin{array}{l}--- \\
--- \\
--- \\
--- \\
25\end{array}$ \\
\hline G & $\begin{array}{l}1 \\
2 \\
3 \\
4 \\
5 \\
6\end{array}$ & $\begin{array}{l}\text { SYMMETRIC X } \\
\text { SYMMETRIC Z } \\
\text { ASYMMETRIC X } \\
\text { ASYMMETRIC Z } \\
\text { LATERAL Y } \\
\text { PINCH-IN }\end{array}$ & $\begin{array}{l}40 \\
--- \\
12 \\
--- \\
--- \\
---\end{array}$ & $\begin{array}{l}40 \\
-12 \\
-12 \\
-\cdots\end{array}$ & \begin{tabular}{l|}
--- \\
35 \\
\hdashline 15 \\
$-\cdots$ \\
---
\end{tabular} & $\begin{array}{l}-\cdots-- \\
35 \\
-15 \\
--- \\
---\end{array}$ & $\mid \begin{array}{l}--- \\
--- \\
-- \\
--- \\
-10\end{array}$ & $\begin{array}{l}-- \\
--- \\
-- \\
-- \\
-10\end{array}$ & $\begin{array}{l}--- \\
--- \\
--- \\
-- \\
30 \\
---\end{array}$ \\
\hline
\end{tabular}

FIGURE 6. - CENTAUR CSS STIFFNESS TEST CONDITIONS. 


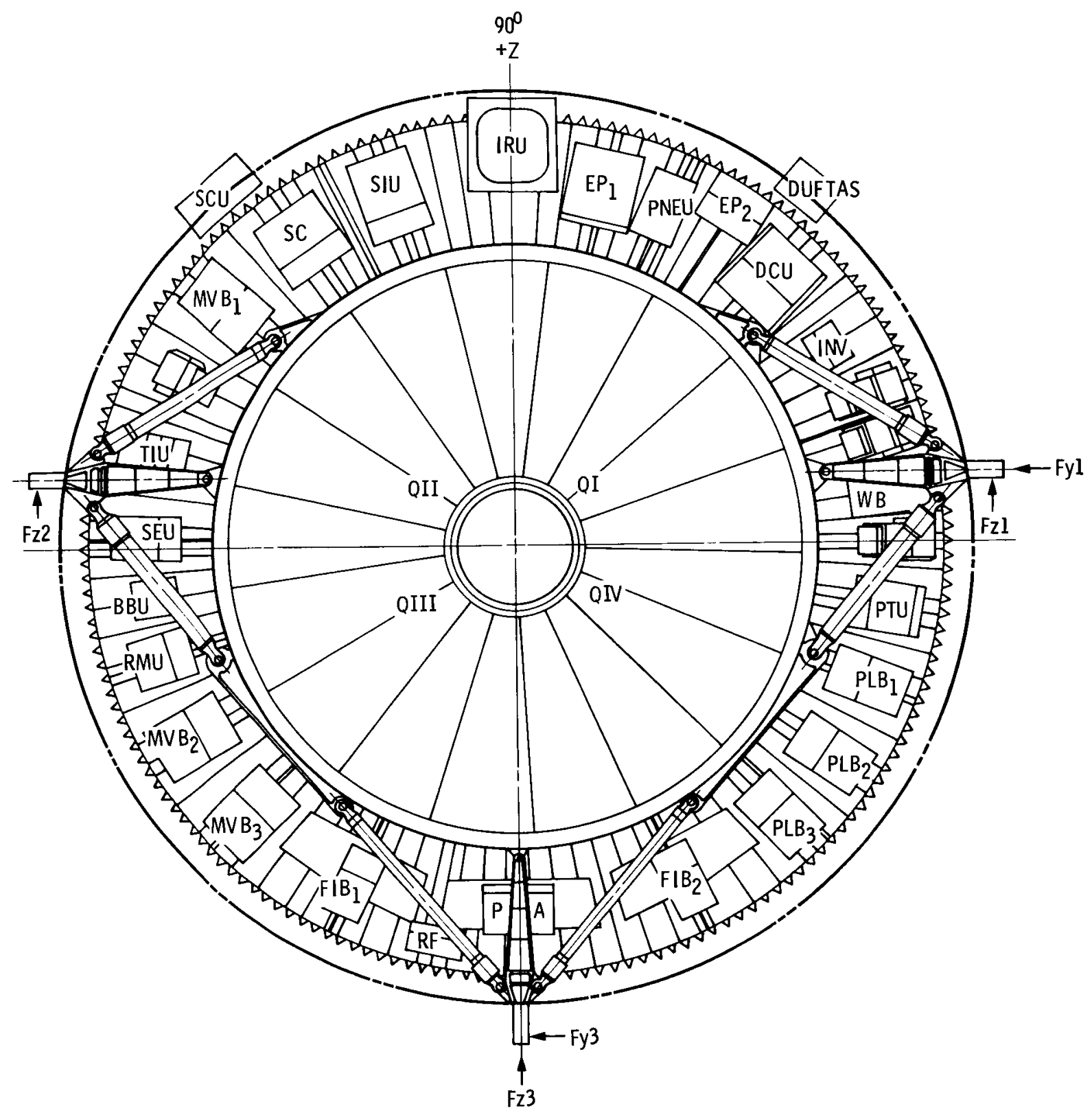

\begin{tabular}{|c|l|r|r|r|c|c|}
\hline \multicolumn{2}{|c|}{ TEST CONDITION } & \multicolumn{4}{|c|}{ APPLIED $L O A D, 10^{3}$ Ib } \\
\hline $\begin{array}{c}\text { NUM- } \\
\text { BER }\end{array}$ & DESCRIPTION & FZ1 & FZ2 & Fyl & Fy3 & FZ3 \\
\hline 1 & SYMMETRIC Z & 28 & 28 & --- & --- & -- \\
2 & ASYMMETRIC Z & -28 & 28 & --- & --- & -- \\
3 & SINGLF Z & 28 & --- & -- & --- & -- \\
4 & PIN FRICTION Y & --- & --- & 3 & --- & -- \\
5 & SINGLE Y & --- & --- & -- & 13 & -- \\
6 & PIN FRICTION Z & --- & --- & --- & -- & 3 \\
\hline
\end{tabular}

FIGURE 7. - CENGAUR G FORWARD ADAPTER STIFFNESS TEST CONDITIONS. 


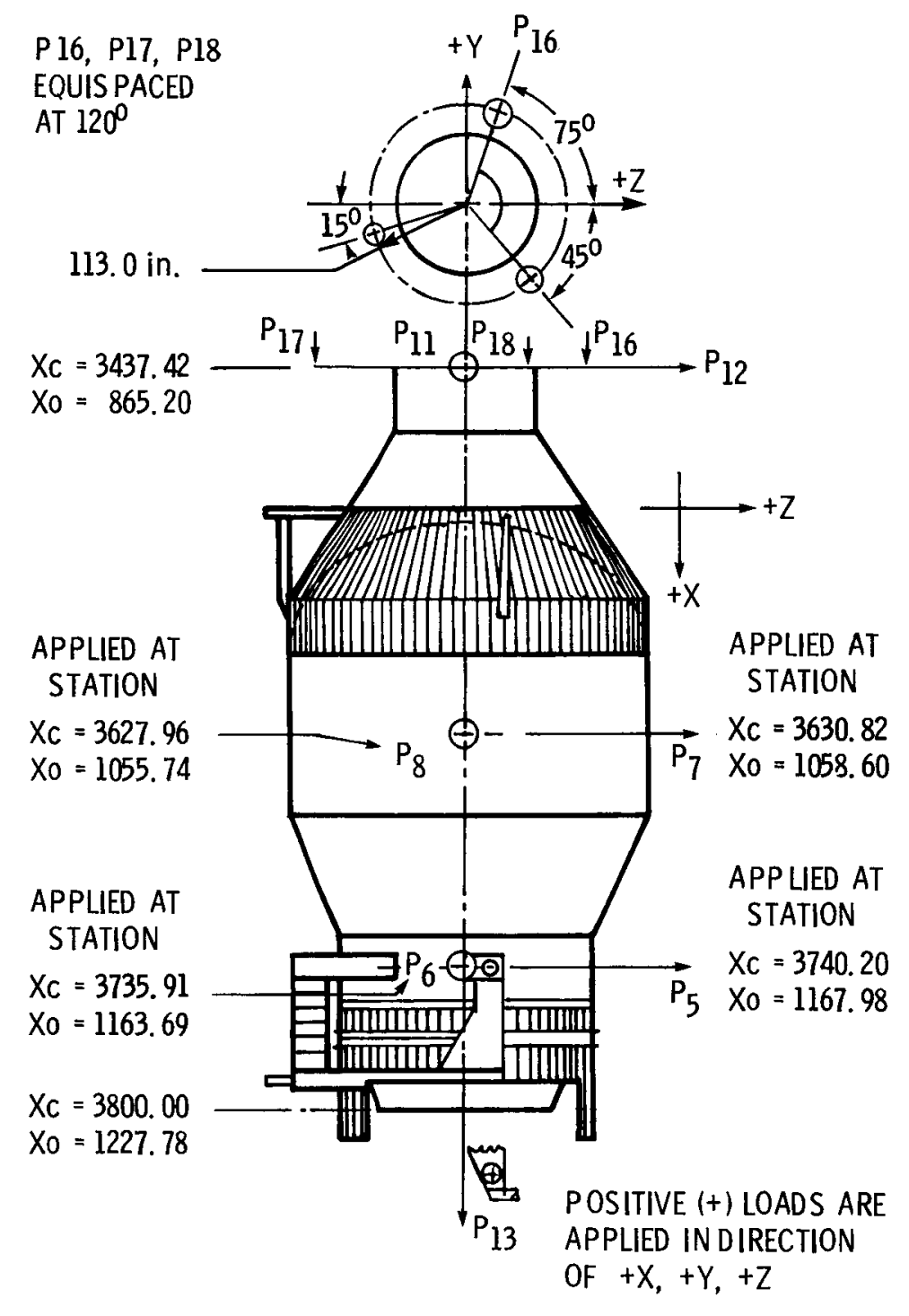

\begin{tabular}{|c|c|c|c|c|c|c|c|c|c|c|}
\hline \multirow{2}{*}{$\begin{array}{c}\text { TEST } \\
\text { CONDITION }\end{array}$} & \multicolumn{10}{|c|}{ APPLIED LOAD, 103 Ib } \\
\cline { 2 - 10 } & P5 & P6 & P7 & P8 & P11 & P12 & P13 & P16 & P17 & P18 \\
\hline 1 & --- & -- & -- & -- & ---- & ----- & --- & 15 & 15 & 15 \\
2 & --- & -- & -- & -- & $51-10$ & ---- & --- & -- & -- & -- \\
3 & --- & -- & -- & -- & --- & $51-20$ & --- & -- & -- & -- \\
4 & --- & -- & 15 & -- & ---- & ---- & --- & -- & -- & -- \\
5 & --- & -- & -- & 15 & ---- & ---- & --- & -- & -- & -- \\
6 & --- & -- & -- & -- & ---- & ---- & 100 & -- & -- & -- \\
7 & 100 & -- & -- & -- & ---- & ---- & --- & -- & -- & -- \\
8 & --- & 50 & -- & -- & ---- & --- & --- & -- & -- & -- \\
\hline
\end{tabular}

FIGURE 8. - CENTAUR G-PRIME CARGO ELEMENT STIFFNESS TEST CONDITIONS. 

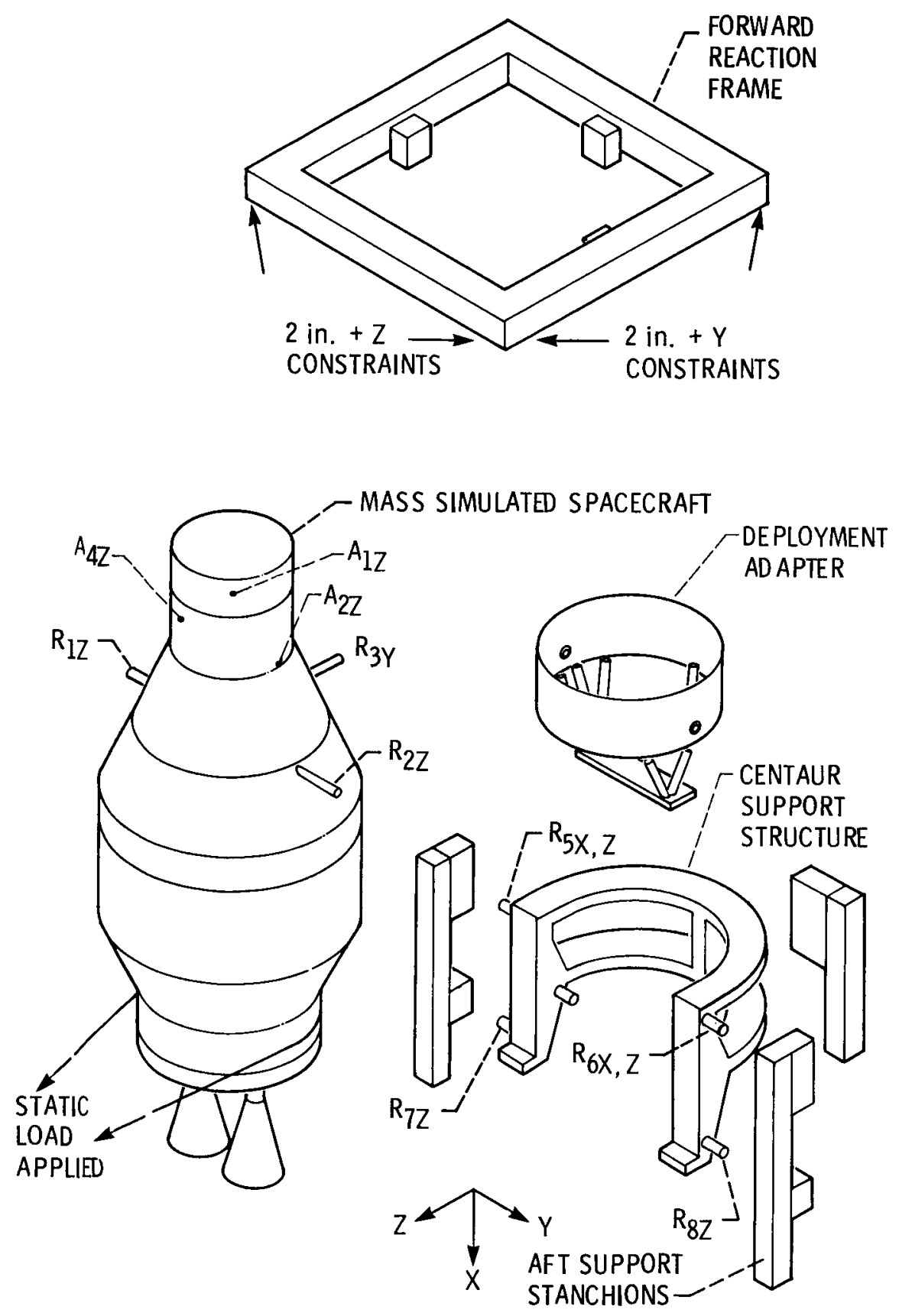

FIGURE 9. - TEST SET-UP FOR CENTAUR G-PRIME STEP-RELAXATION TEST. 


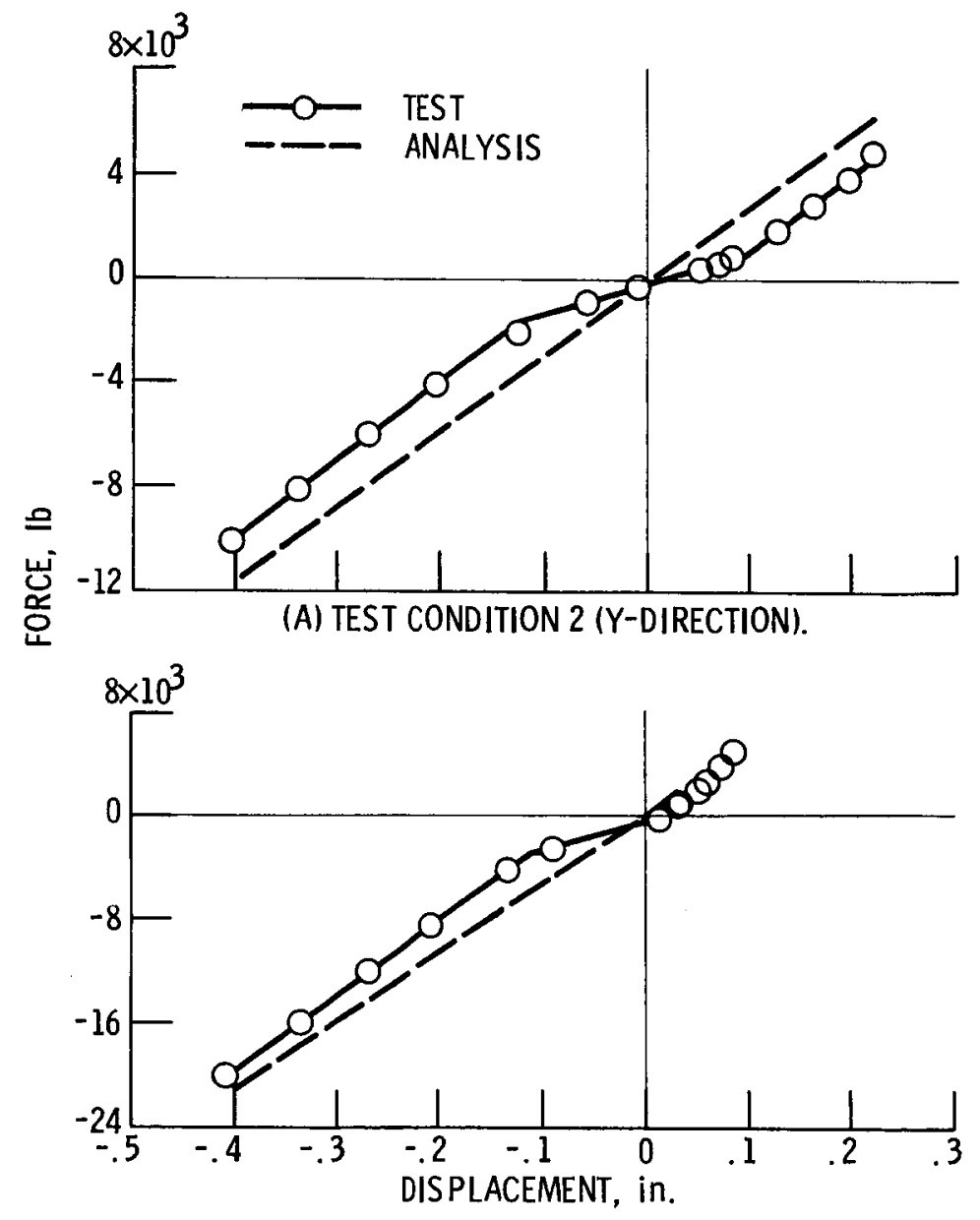

(B) TEST CONDITION 3 (Z-DIRECTION).

FIGURE 10. - NONLINEAR STIFFNESS OF CENTAUR G-PRIME IN CARGO ELEMENT CONFIGURATION (LOAD POINT RES PONSE). 


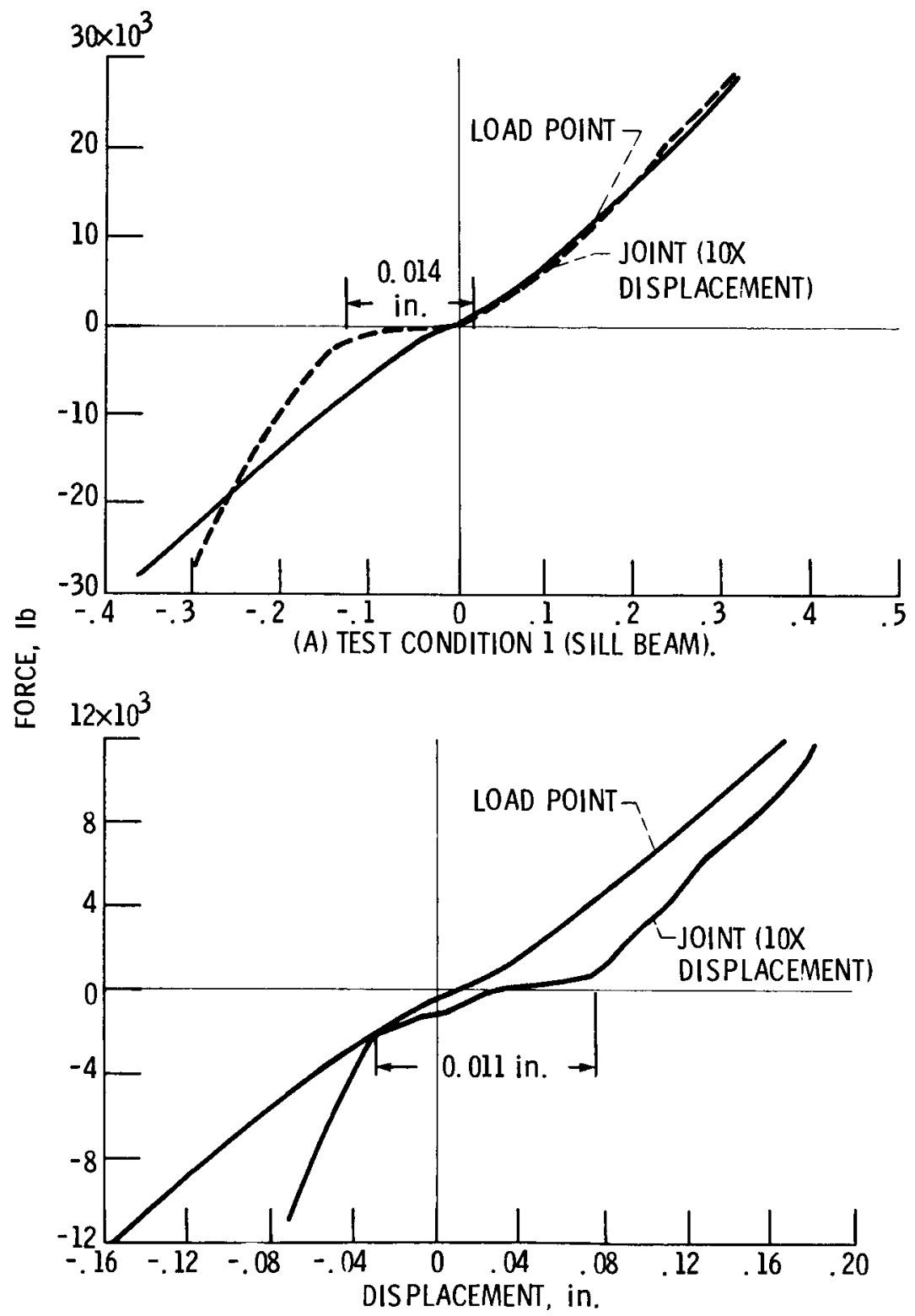

(B) TEST CONDITION 5 (KEEL BEAM).

FIGURE 11. - NONLINEAR STIFFNESS OF CENTAUR G FORWARD AD APTER. 


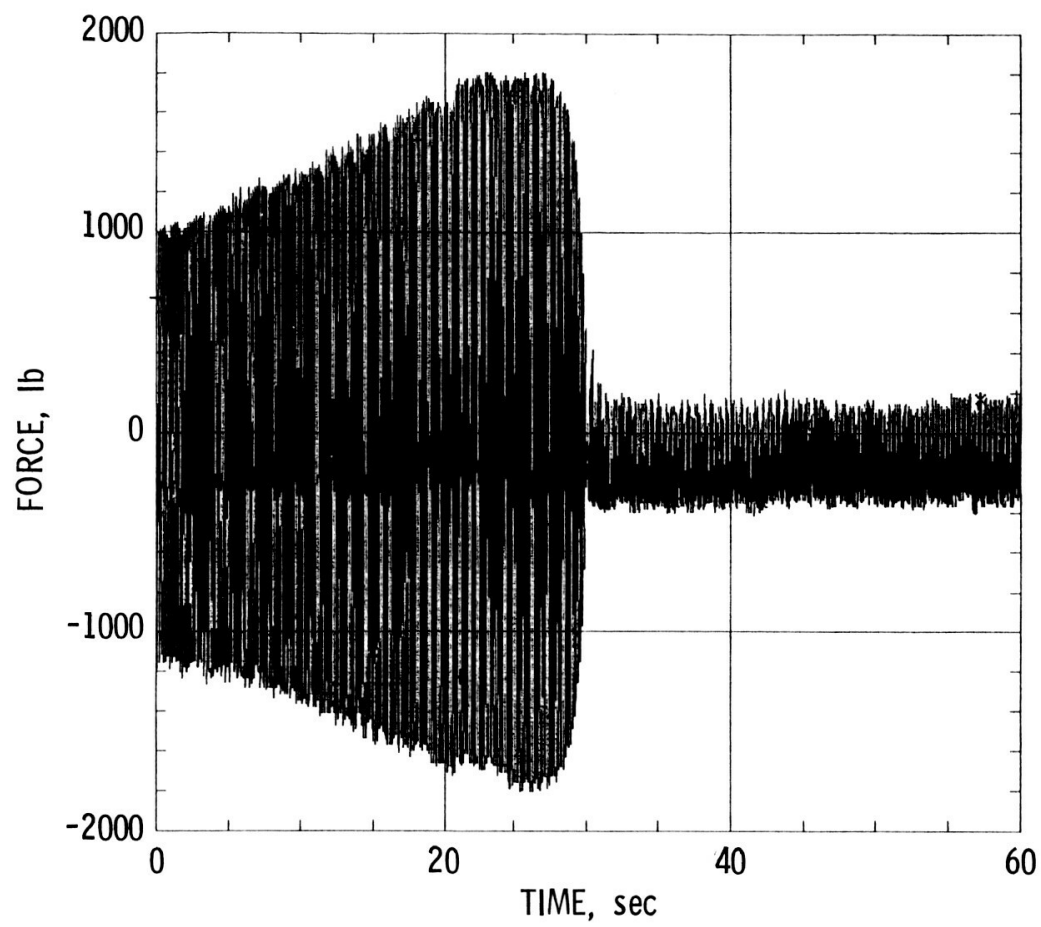

FIGURE 12. - TIME HISTORY OF SILL TRUNNION REACTION FORCE (RIZ) DURING SINE SWEEP EXCITATION (FORWARD PITCH MODE).

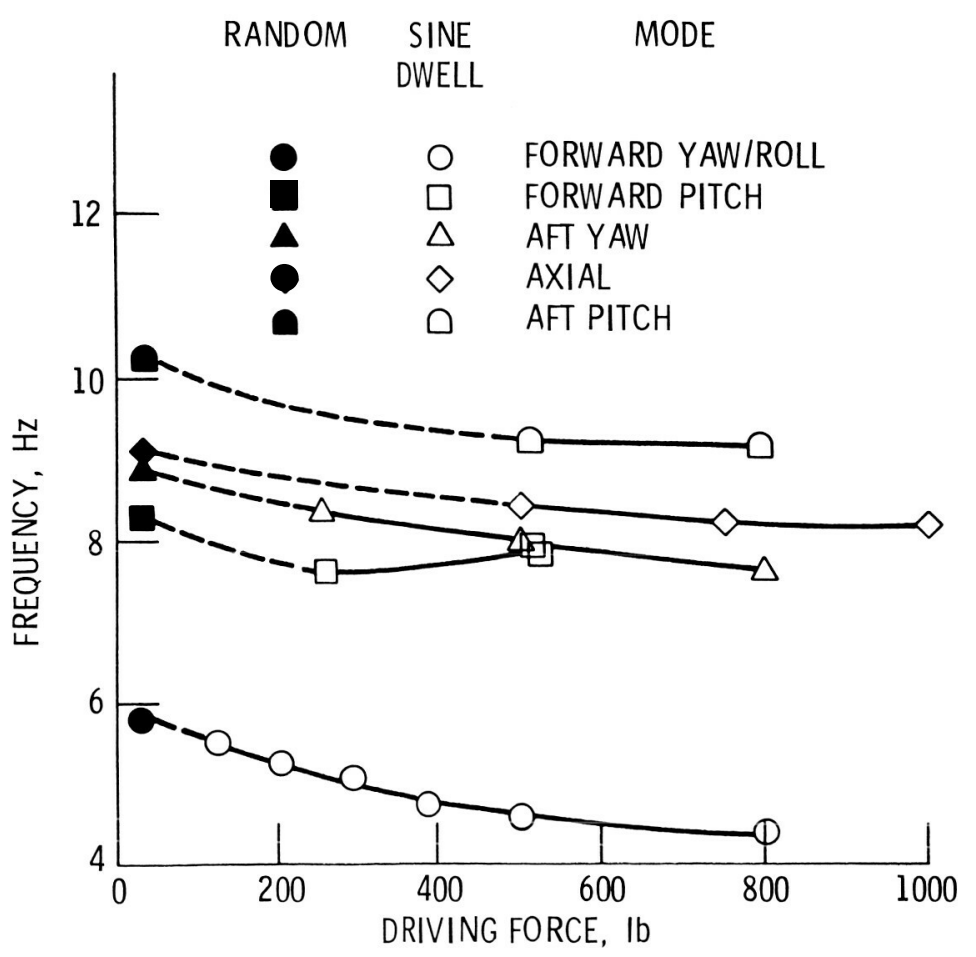

FIGURE 13. - EFFECT OF EXCITATION FORCE ON NATURAL FREQUENCY OF CENTAUR G-PRIME CARGO ELEMENT MODES (LOX TANK FULL OF WATER). 


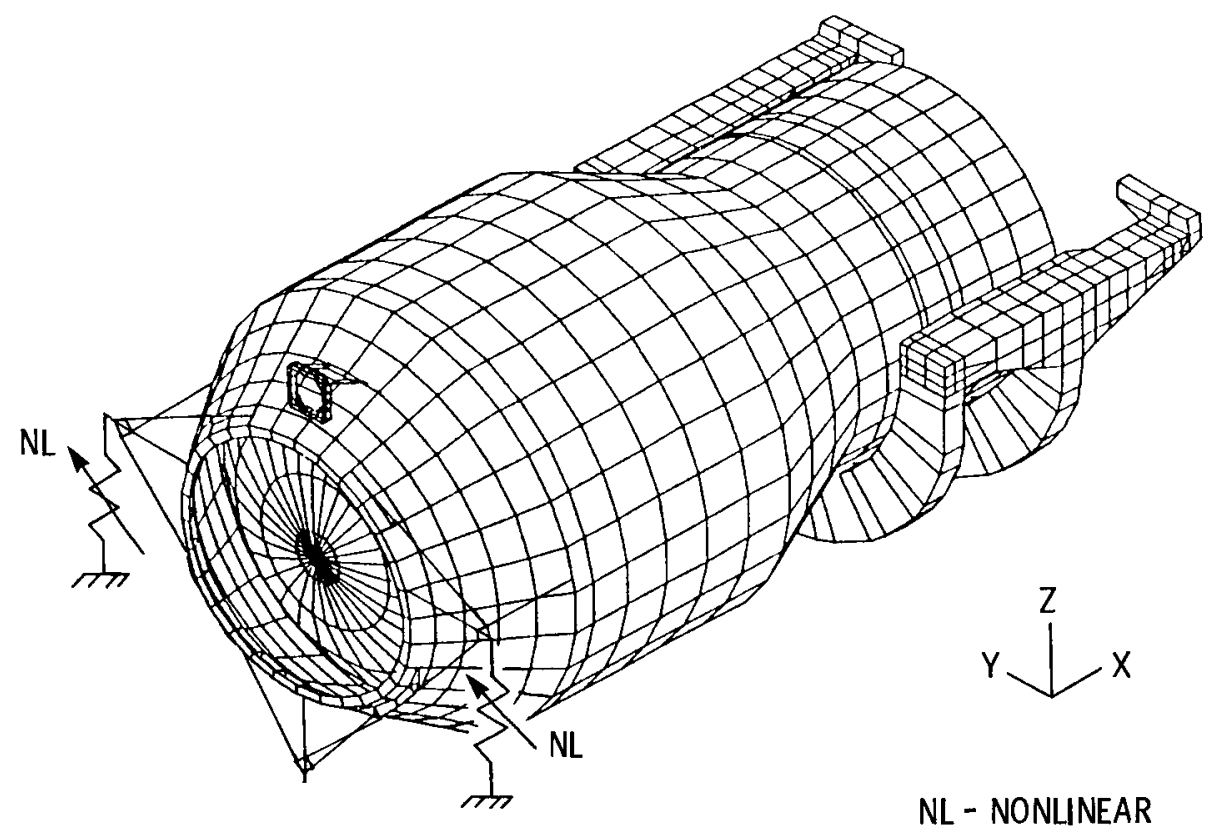

FIGURE 14. - CENTAUR G-P RIME NONLINEAR MODEL.

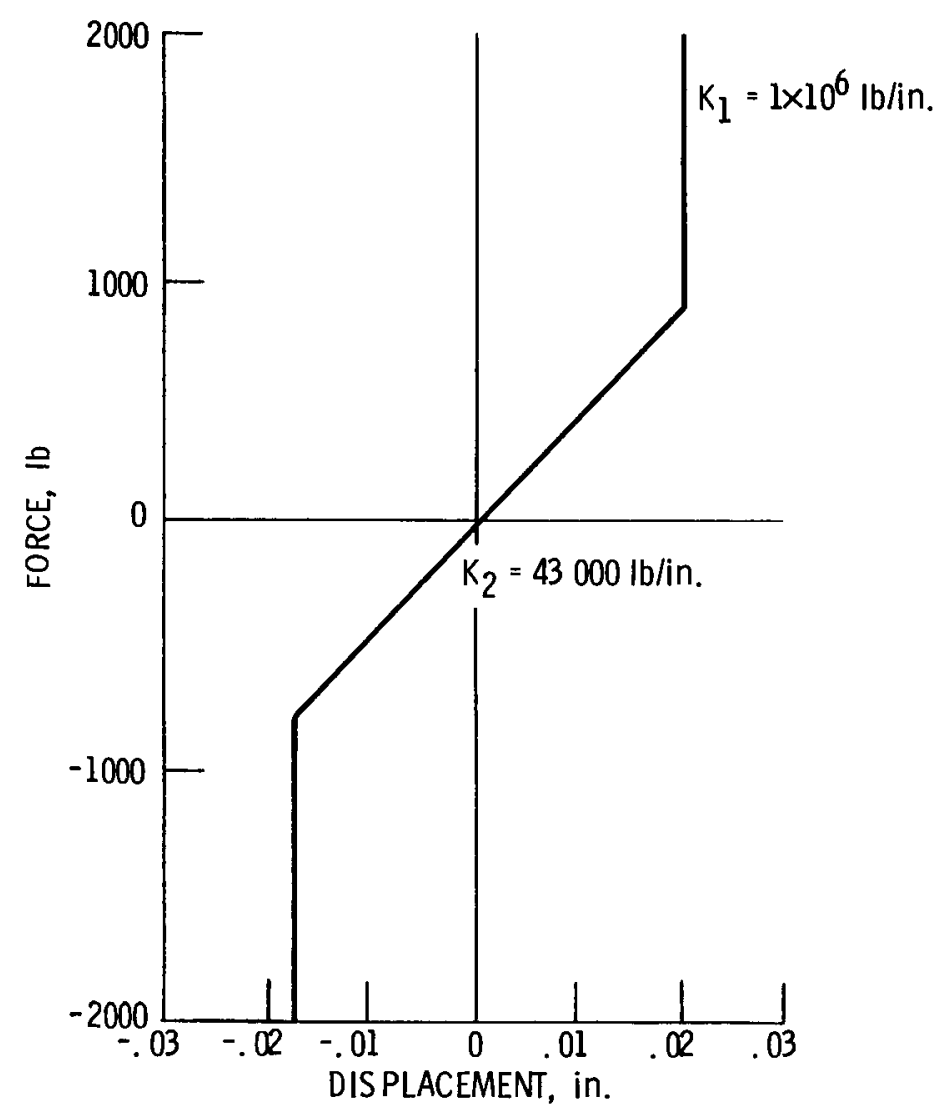

FIGURE 15. - CENTAUR G-PRIME NONLINEAR MODEL NOLINI ELEMENT PROPERTIES. 


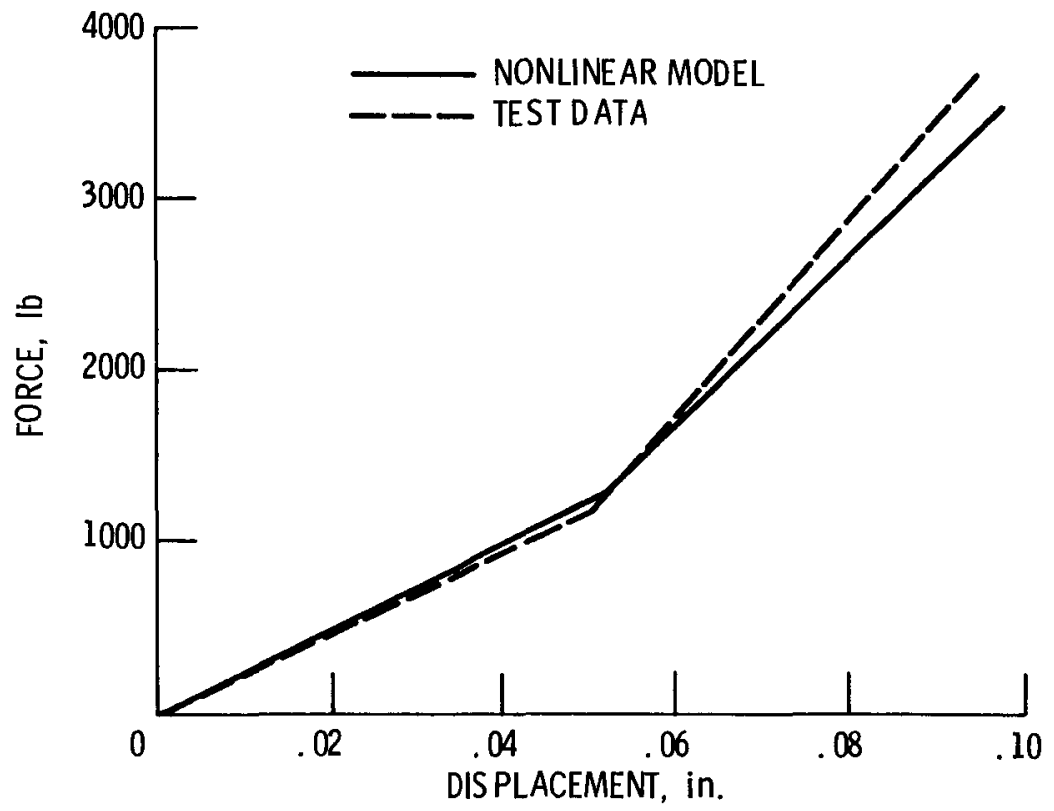

FIGURE 16. - COMPARISON OF STIFFNESS OF NONLINEAR MODEL TO STATIC TEST DATA. 


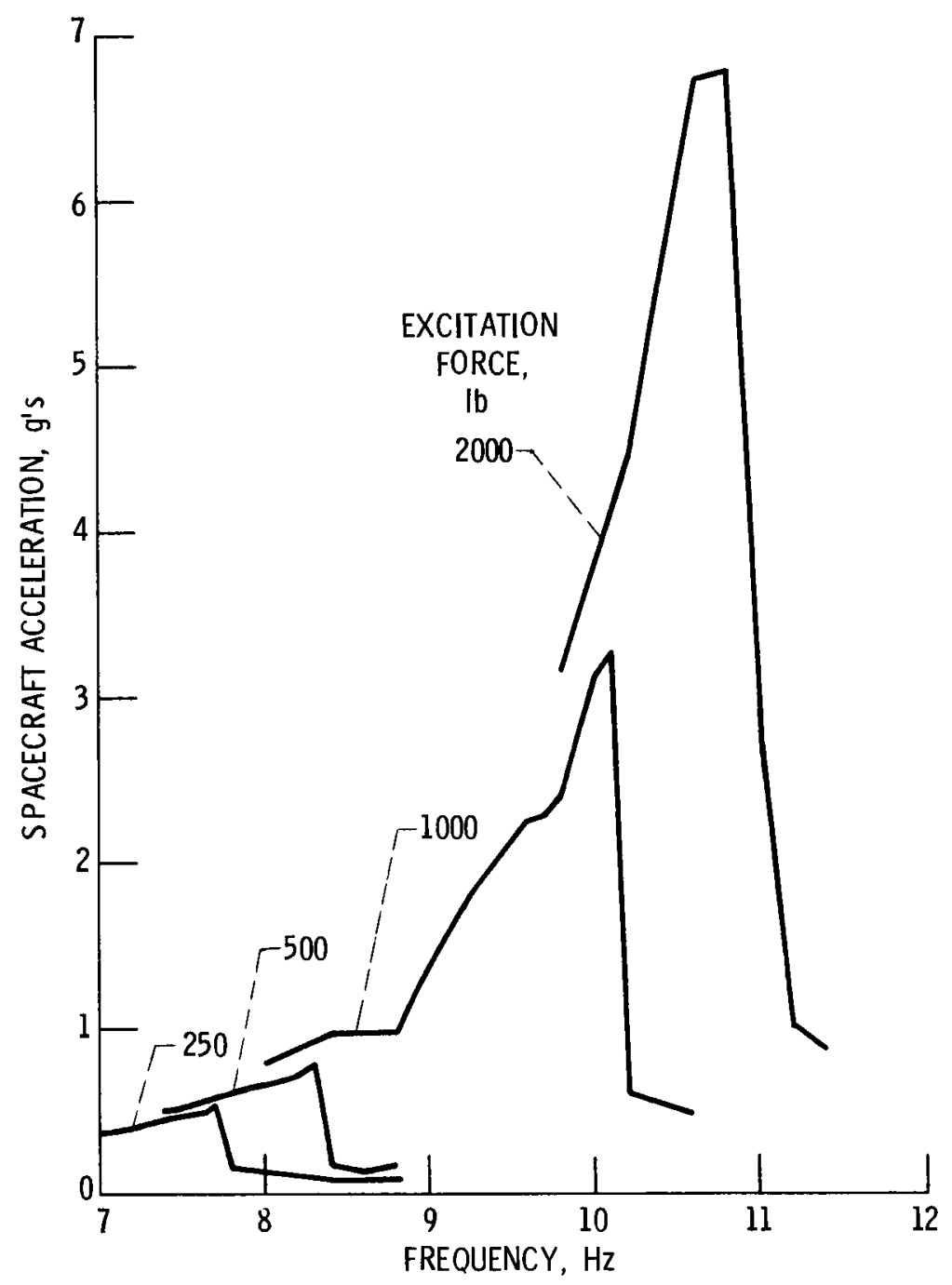

FIGURE 17. - RESPONSE OF CENTAUR G-PRIME NONLINEAR MODEL TO SIMULATED SINE SWEEP EXCITATION. 


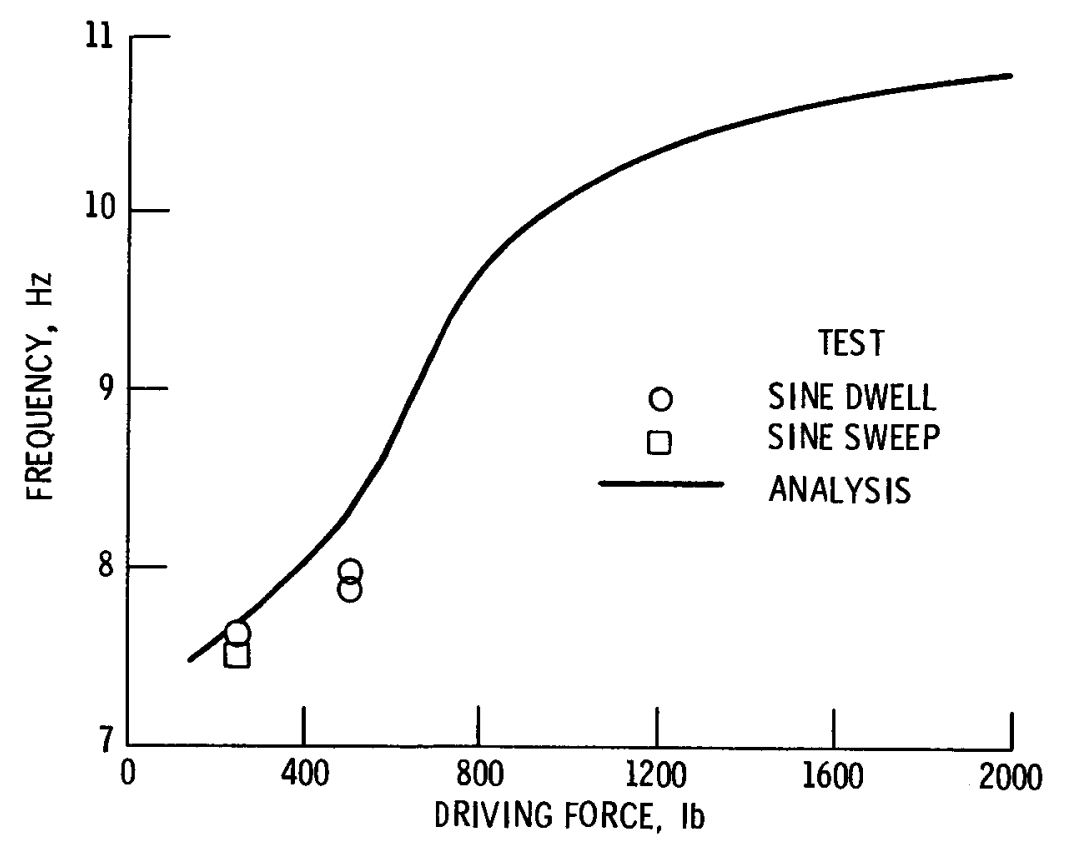

FIGURE 18. - EFFECT OF DRIVING FORCE ON FREQUENCY OF CENTAUR G-PRIME FORWARD PITCH MODE. 

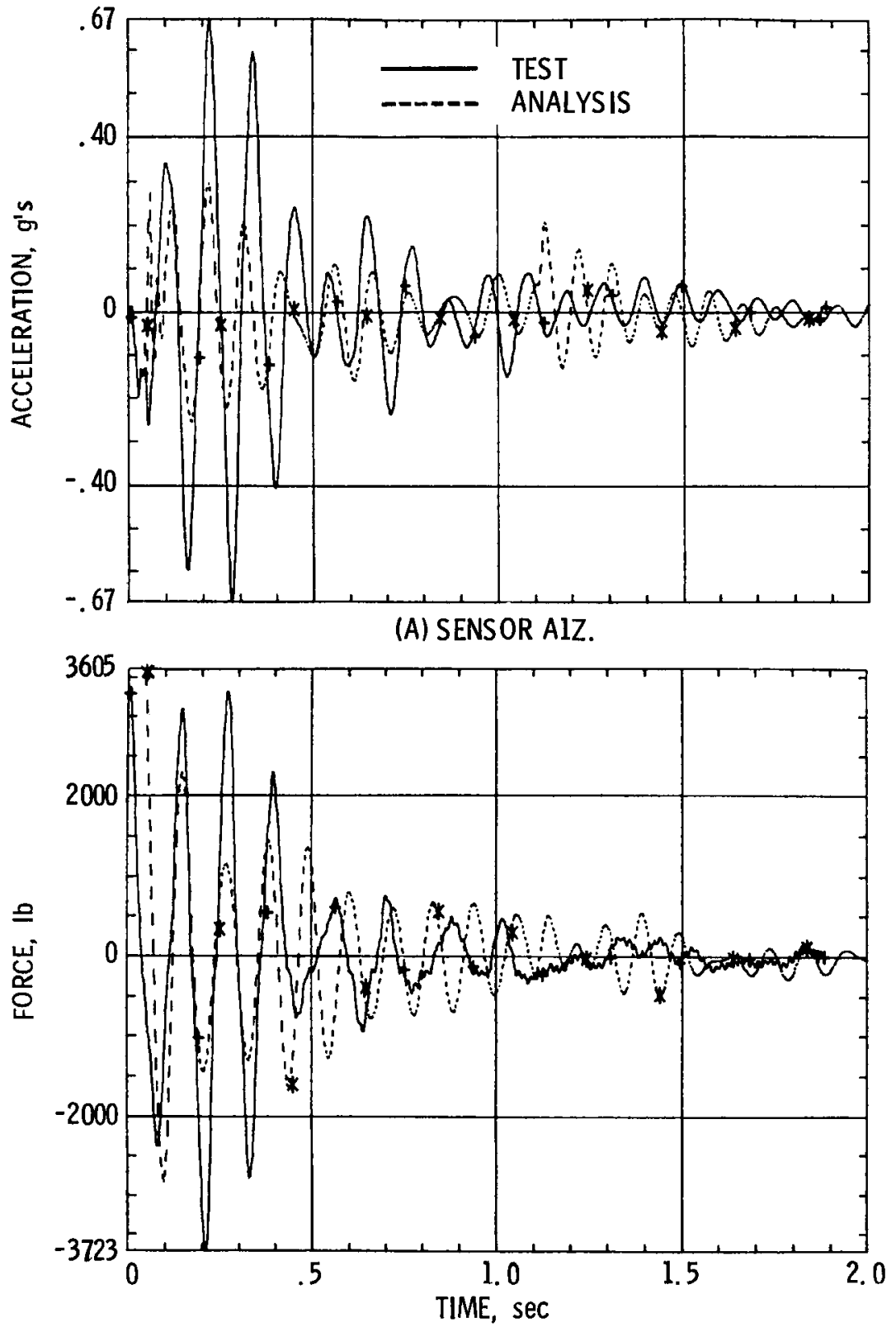

(B) SENSOR RIZ.

FIGURE 19. - COMPARISON OF STEP-RELAXATION TIME HISTORY WITH GP 5. O MODEL. 

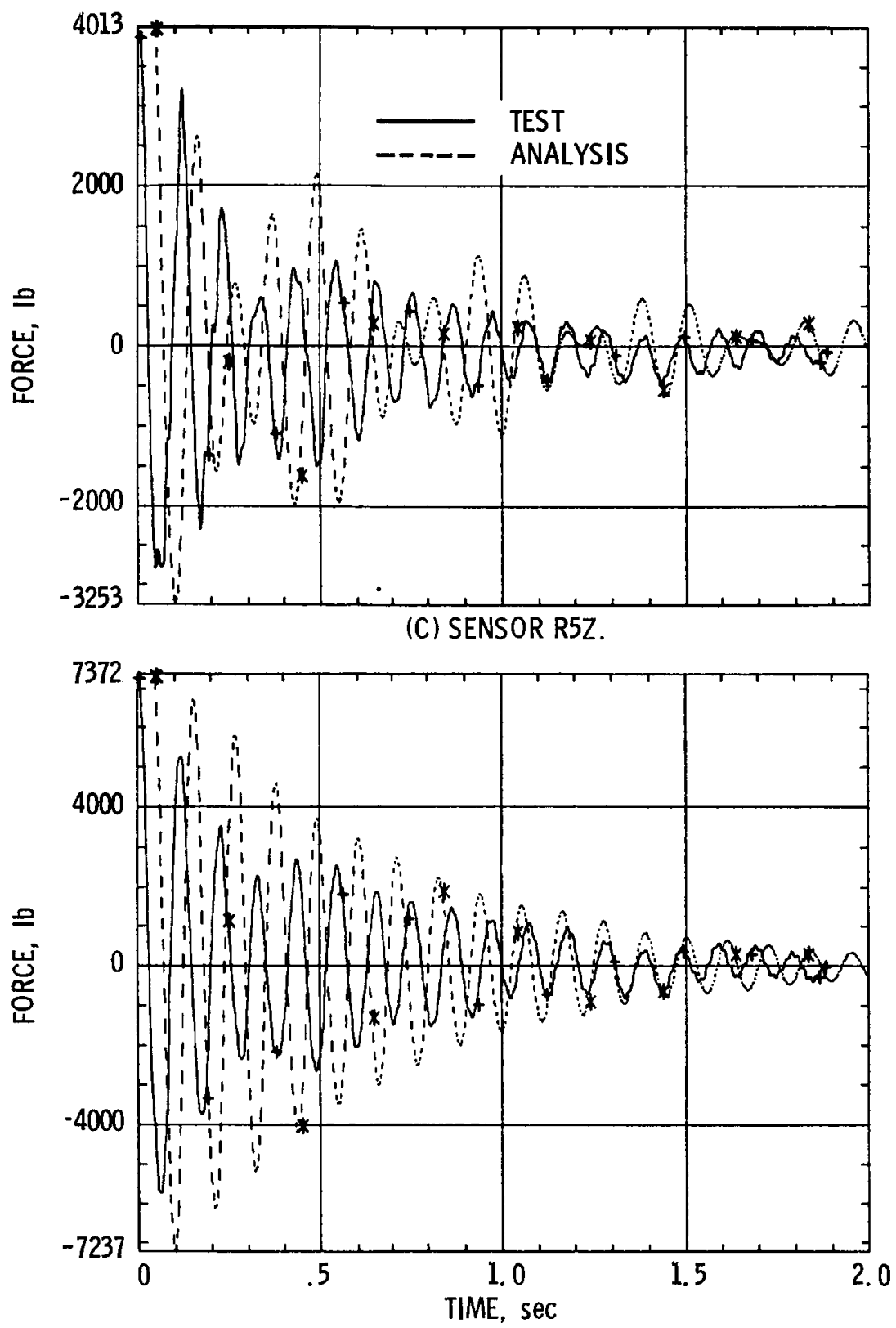

(D) SENSOR R7Z.

FIGURE 19. - CONCLUDED. 

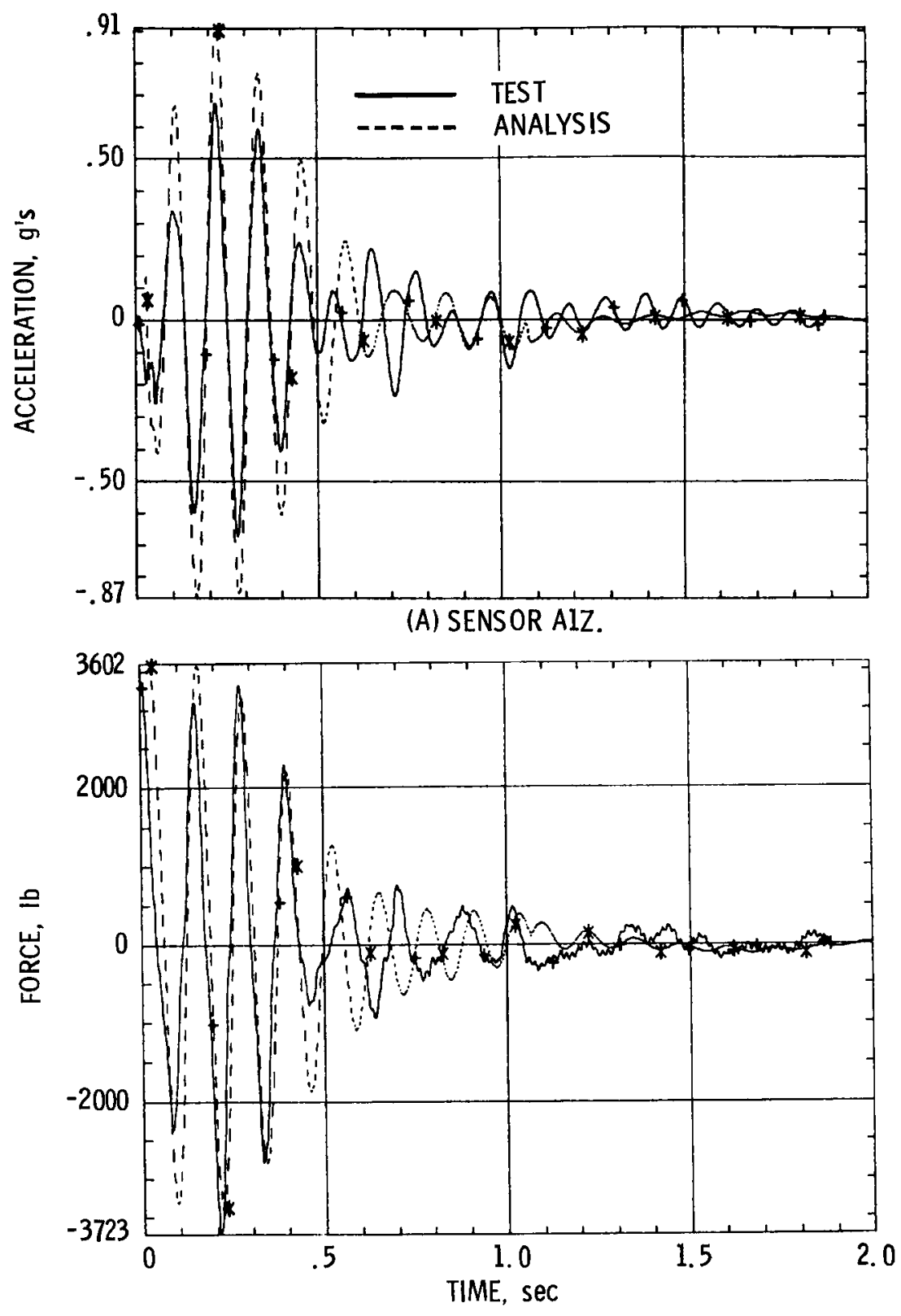

(B) SENSOR RIZ.

FIGURE 20. - COMPARISON OF STEP-RELAXATION TIME HISTORY WITH GP 6.0 M MODEL. 

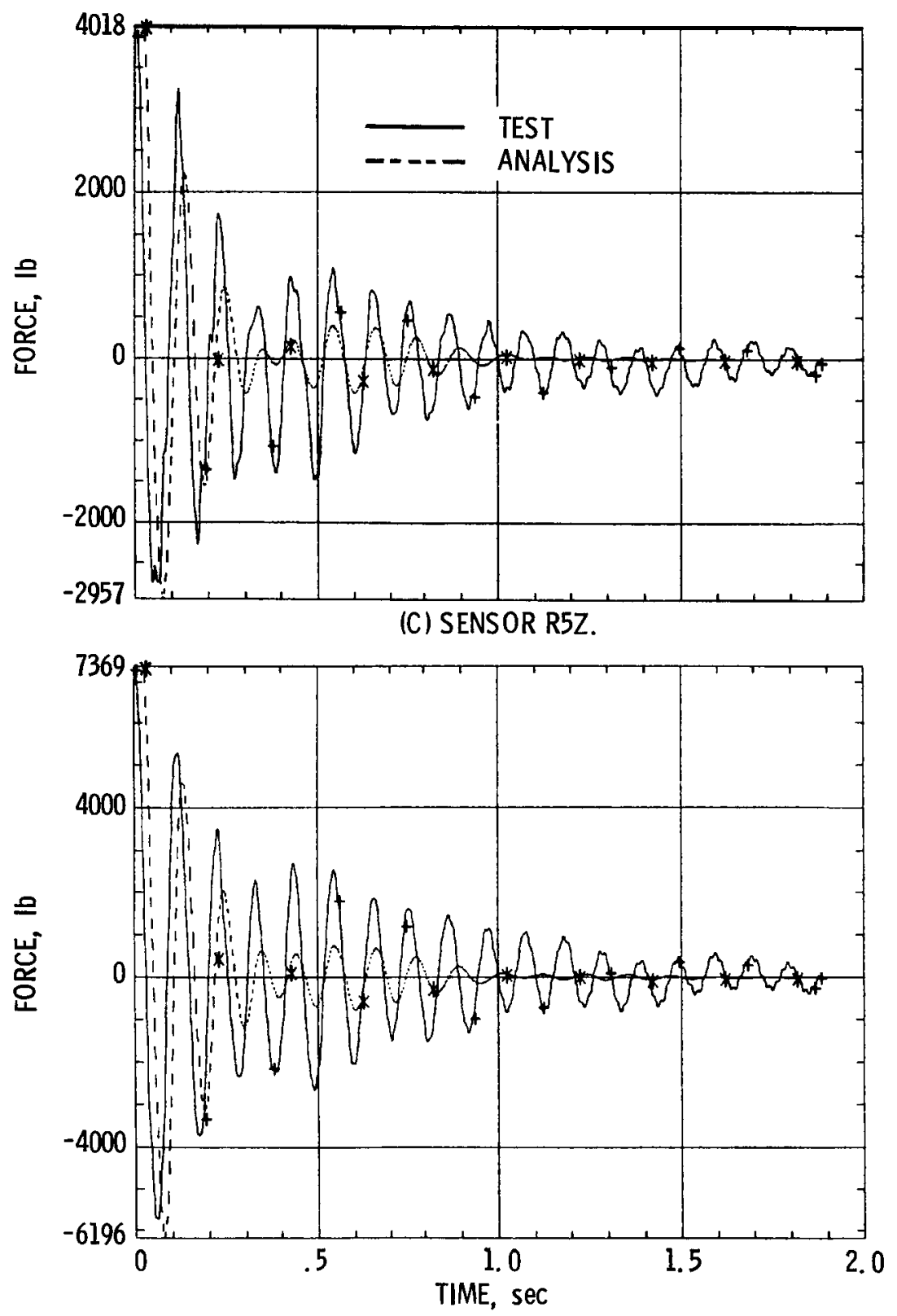

(D) SENSOR R7Z.

FIGURE 20. - CONCLUDED. 

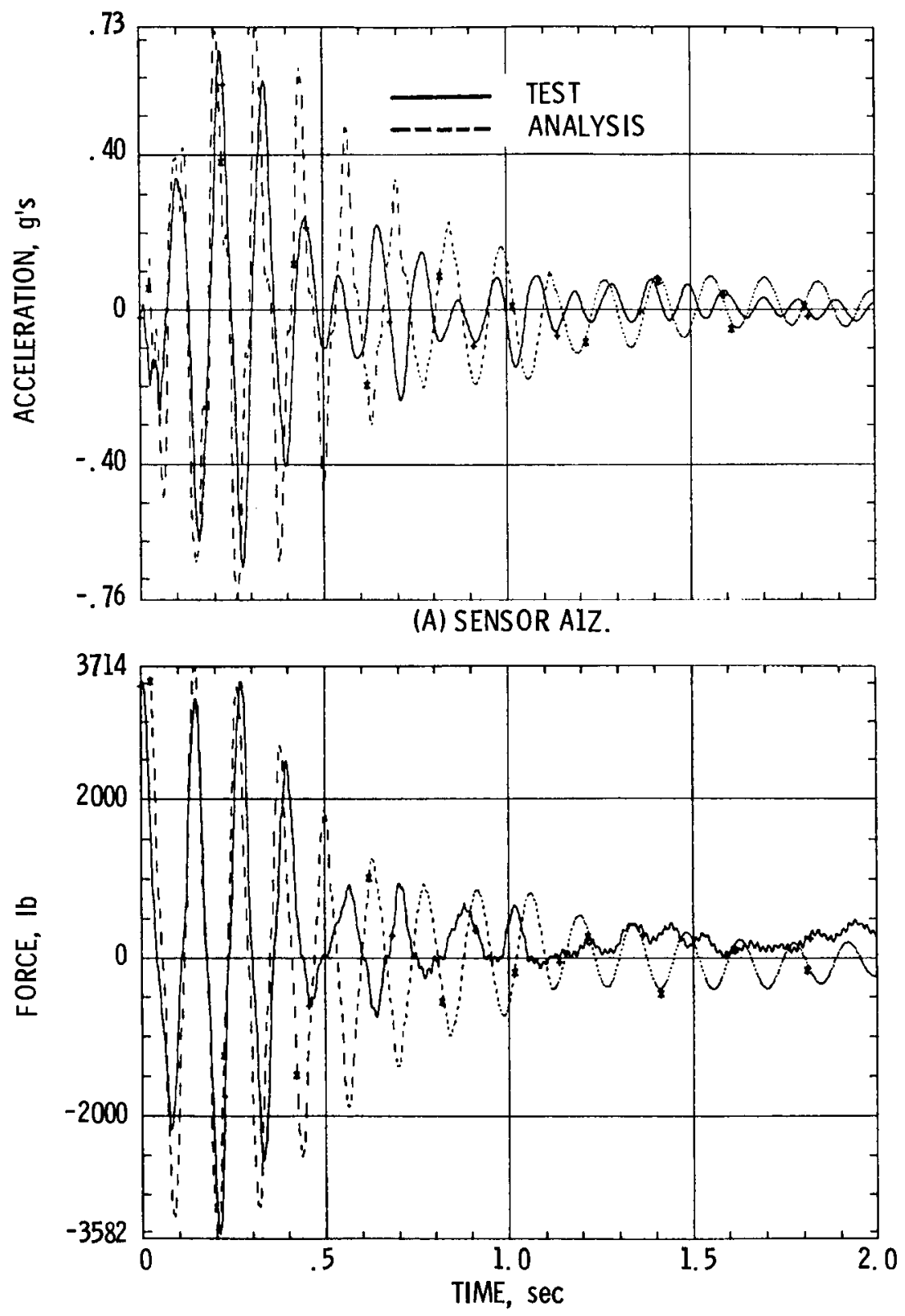

(B) SENSOR RIZ.

FIGURE 21. - COMPARISON OF STEP-RELAXATION TIME HISTORY WITH GP 6.0 NL MODEL. 

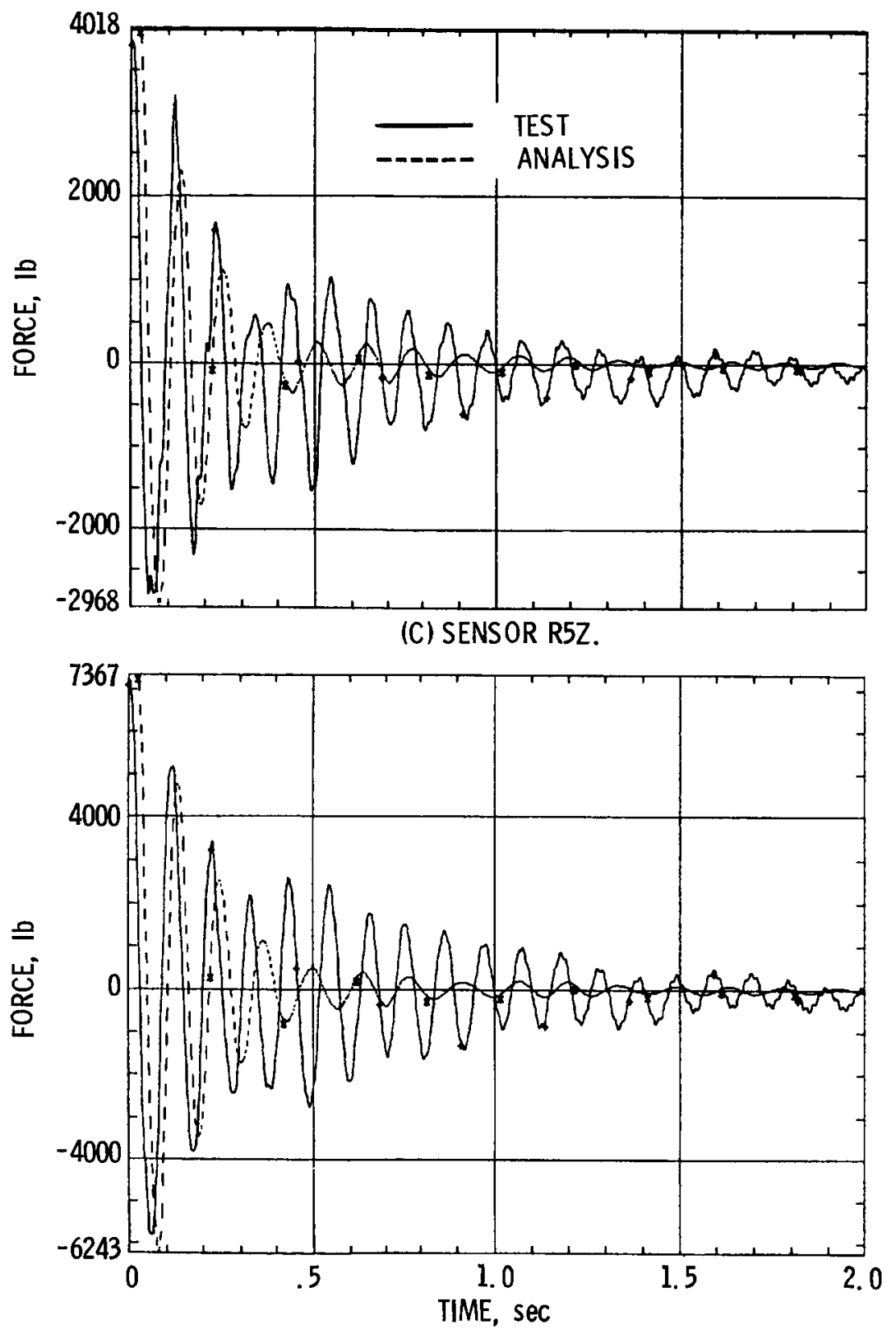

(D) SENSOR R7Z.

FIGURE 2l. - CONCLUDED. 


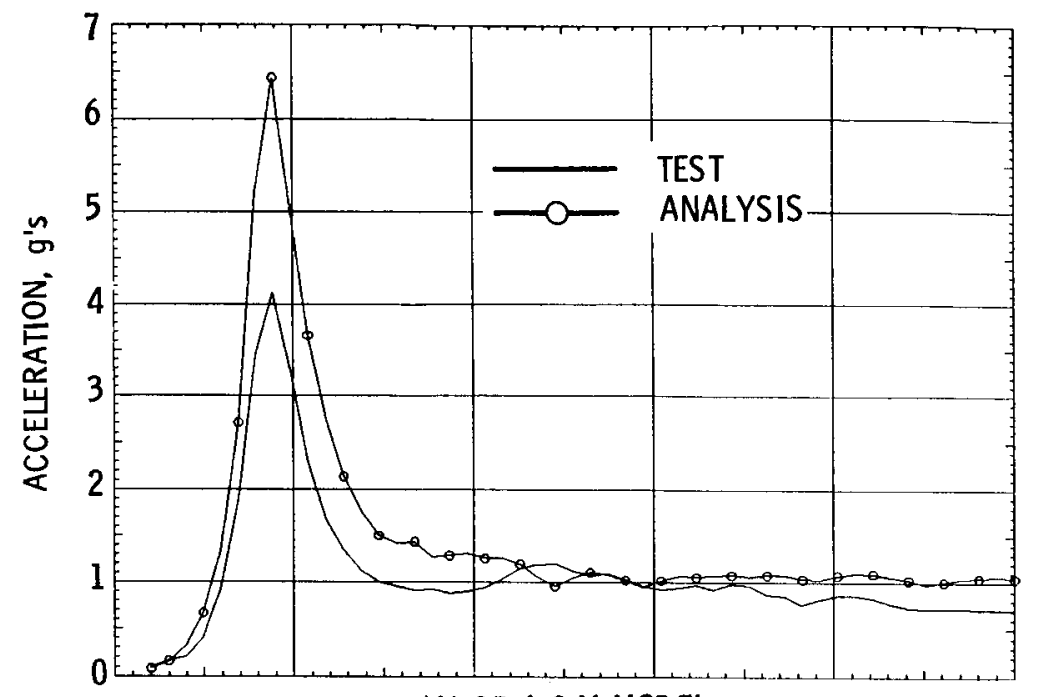

(A) GP 6.0 M MODEL.

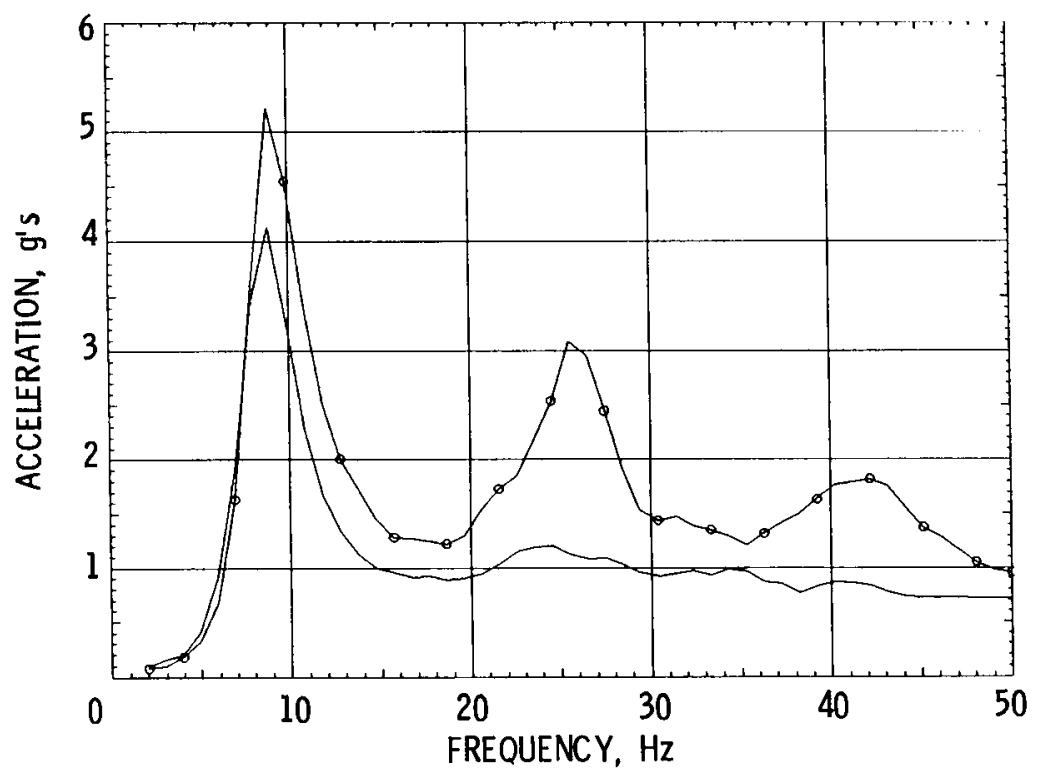

(B) GP 6.0 NL MODEL.

FIGURE 22. - COMPARISON OF SIMULATED SPACECRAFT RES PONSE SPECTRA FOR STEP-RELAXATION TEST. 


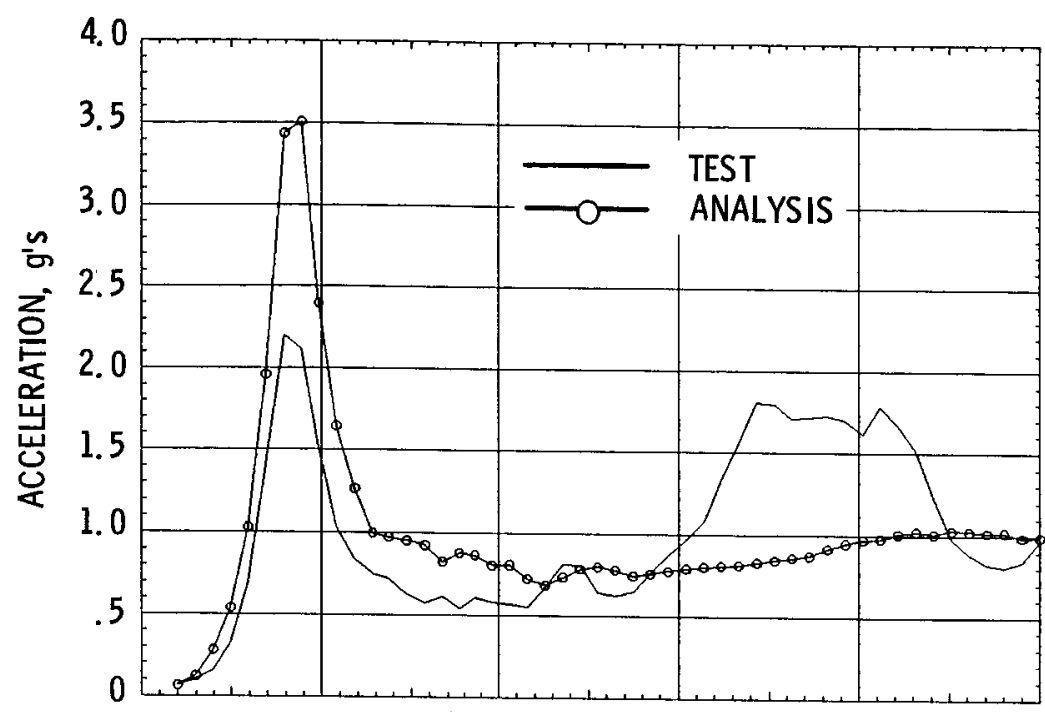

(A) GP 6.0 M MODEL.

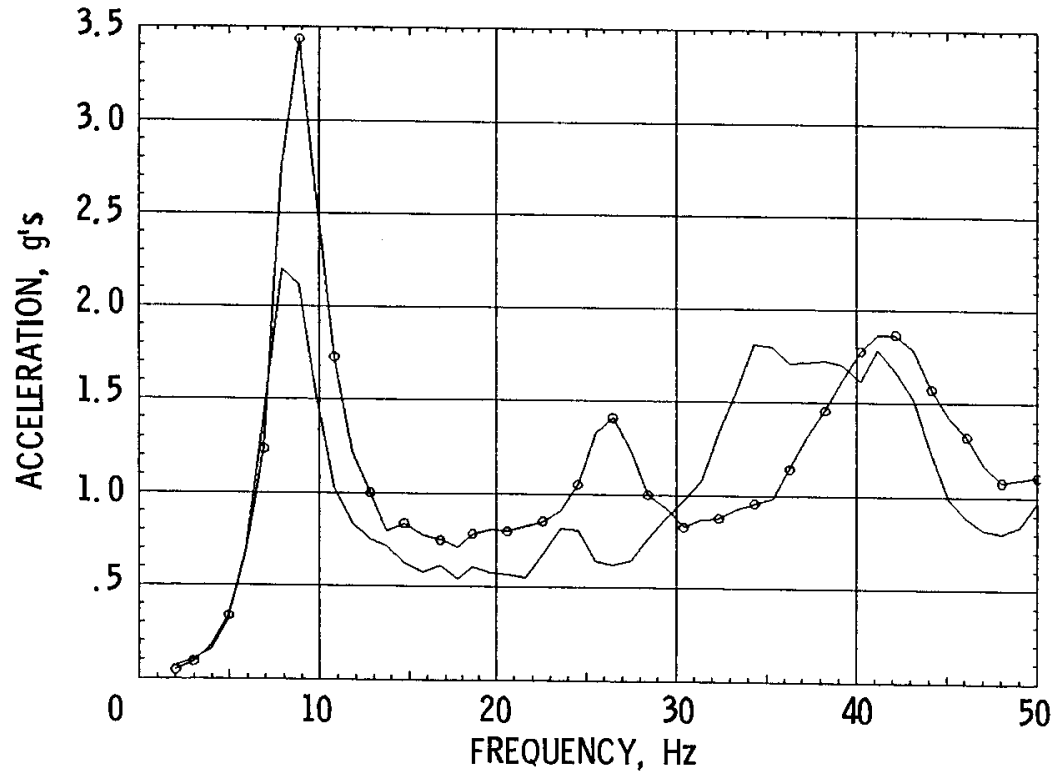

(B) GP 6.0 NL MODEL.

FIGURE 23. - COMPARISON OF INTERFACE RES PONSE S PECTRA FOR STEP-RELAXATION TEST. 


\begin{tabular}{|c|c|c|}
\hline $\begin{array}{l}\text { 1. Report No. } \\
\text { NASA TM-88941 }\end{array}$ & 2. Government Accession No. & 3. Recipient's Catalog No. \\
\hline \multirow{2}{*}{\multicolumn{2}{|c|}{$\begin{array}{l}\text { 4. Title and Subtitle } \\
\text { The Effect of Nonlinearities on the Dynamic Response } \\
\text { of a Large Shuttle Payload }\end{array}$}} & $\begin{array}{l}\text { 5. Report Date } \\
\text { January } 1987\end{array}$ \\
\hline & & 6. Performing Organization Code \\
\hline \multirow{2}{*}{\multicolumn{2}{|c|}{$\begin{array}{l}\text { 7. Author(s) } \\
\text { Timothy L. Sullivan and Kelly S. Carney }\end{array}$}} & $\begin{array}{l}\text { 8. Performing Organization Report No. } \\
\text { E-3387 }\end{array}$ \\
\hline & & $\begin{array}{r}\text { 10. Work Unit No. } \\
927-60-00\end{array}$ \\
\hline \multirow{2}{*}{\multicolumn{2}{|c|}{$\begin{array}{l}\text { 9. Performing Organization Name and Address } \\
\text { National Aeronautics and Space Administration } \\
\text { Lewis Research Center } \\
\text { Cleveland, Ohio } 44135\end{array}$}} & 11. Contract or Grant No. \\
\hline & & \multirow{2}{*}{$\begin{array}{l}\text { 13. Type of Report and Period Covered } \\
\text { Technical Memorandum }\end{array}$} \\
\hline \multicolumn{2}{|l|}{ 12. Sponsoring Agency Name and Address } & \\
\hline $\begin{array}{l}\text { National Aeronautics and Space Administrat } \\
\text { Washington, D.C. } 20546\end{array}$ & ton & 14. Sponsoring Agency Code \\
\hline \multirow{2}{*}{\multicolumn{3}{|c|}{$\begin{array}{l}\text { 15. Supplementary Notes } \\
\text { Prepared for the } 28 \text { th Structures, Structural Dynamics, and Materials Conference, } \\
\text { sponsored by the American Institute of Aeronautics and Astronautics, Monterey, } \\
\text { California, Apr } 116-8,1987 \text {. }\end{array}$}} \\
\hline & & \\
\hline \multicolumn{3}{|l|}{ 16. Abstract } \\
\hline \multicolumn{3}{|c|}{$\begin{array}{l}\text { The STS Centaur was designed to be a high energy upper stage for use with the } \\
\text { Space Shuttle. Two versions were designed and under development when the program } \\
\text { was cancelled. The first version, designated G-prime, was designed for planetary } \\
\text { missions. The second version, designated G, was designed to place spacecraft in } \\
\text { geosynchronous orbit. As a part of the STS Centaur finite-element model veri- } \\
\text { fication effort, test articles of both versions were subjected to a serles of } \\
\text { static tests. In addition the Centaur G-prime test article was subjected to a } \\
\text { series of dynamic tests including a modal survey. Both the static and dynamic } \\
\text { tests showed that nonlinearities existed in the Centaur and its support system. } \\
\text { The support system included flight-like latches. The nonlinearities were par- } \\
\text { ticularly apparent in tests that loaded the forward support structure of the } \\
\text { Centaur. These test results were used to aid in the development of two improved } \\
\text { finite-element models. The first was a linear model, while the second contained } \\
\text { nonlinear elements at the boundaries. Results from both models were compared } \\
\text { with the transient response obtained from a step-relaxation or twang test. The } \\
\text { linear model was able to accurately match the low frequency response found in } \\
\text { the test data. However, only the nonlinear model was able to match higher fre- } \\
\text { quency response that was present in some of the test data. In addition the non- } \\
\text { linear model was able to predict other nonlinear behavior such as the dynamic } \\
\text { "jump" that occurs in systems with nonlinear stiffness. }\end{array}$} \\
\hline 17. Key Words (Suggested by Author(s)) & \multirow{2}{*}{\multicolumn{2}{|c|}{$\begin{array}{l}\text { 18. Distribution Statement } \\
\text { Unc lassified - unlimited } \\
\text { STAR Category } 39\end{array}$}} \\
\hline $\begin{array}{l}\text { Dynamic structural analysis; Nonlinear } \\
\text { systems; Space Shuttle payloads; Centaur } \\
\text { launch vehicle; Dynamic tests; } \\
\text { Static tests }\end{array}$ & & \\
\hline $\begin{array}{l}\text { 19. Security Classif. (of this report) } \\
\text { Unc lass if I ed }\end{array}$ & page) & 21. No. of pages \\
\hline
\end{tabular}

"For sale by the National Technical Information Service, Springfield, Virginia 22161 